\title{
Making Change from Behind a Mask: How Organizations Challenge Guarded Institutions by Sparking Grassroots Activism
}

\author{
Laura Claus \\ University College London \\ 1.claus@ucl.ac.uk \\ Paul Tracey \\ University of Cambridge and University of Melbourne \\ p.tracey@jbs.cam.ac.uk
}

Acknowledgements. We are sincerely grateful to Tima Bansal and three anonymous referees who made such a significant contribution to the development of our work, and whose guidance was truly invaluable. We also thank Royston Greenwood and Sarah Soule for their thoughtful advice, support, and feedback, and the participants of the 2016 Community of Social Innovation (COSI) meeting at Stanford for their constructive comments. Finally, we are deeply indebted to the individuals who facilitated the data collection process in Indonesia, with special thanks to the Syakhroza family and all of our informants who were willing to share their insights and personal stories with us. 


\title{
Making Change from Behind a Mask: How Organizations Challenge Guarded Institutions by Sparking Grassroots Activism
}

\begin{abstract}
We examine how organizations can challenge institutions that are coercively protected by powerful elites - guarded institutions - when they are unable or unwilling to advocate publicly against them. To do so, we draw on an in-depth qualitative study of efforts to combat child marriage in Indonesia. We explore how an international children's rights organization worked alongside local NGOs and activists to disrupt the institution of child marriage through two discrete strategies: the crafting of an alter ego that takes the appearance of a social movement that has emanated from the grassroots but is actually highly organized; and the use of this alter ego to support the incubation of public dissent by means of a high-stakes event. We contribute to the literature by developing a theorized account of how organizations can challenge guarded institutions when they cannot speak out - an important organizational problem that has received limited attention. We also challenge the theoretical distinction that has been drawn between the organizational mobilization of activists, often referred to as astroturfing, and seemingly organic mobilization that is said to emerge at the grassroots.
\end{abstract}

\section{INTRODUCTION}

Each year over 340,000 girls in Indonesia are married before their $18^{\text {th }}$ birthday, 50,000 before their $15^{\text {th }}$ birthday, and in several thousand cases before they have graduated from elementary school (Indonesia DHS, 2012; UNICEF Global Database, 2014) ${ }^{1}$. These marriages are not only legally sanctioned as a result of the country's 1974 marriage act, they are also widely accepted and morally reinforced, particularly in rural areas. Efforts for reform have repeatedly failed, blocked by elements of Indonesia's religious and political establishment who have condemned organizations that dissent, accusing them of blasphemy and a desire to weaken the country's Islamic heritage. As such, child marriage is an example of a guarded institution - an institution that is coercively protected by powerful elites. These elites use their social position to suppress opposition, sanction challengers and protect the status quo.

Our in-depth, longitudinal study examines a campaign led by an international children's rights organization - ICO [a pseudonym] - to disrupt the institution of child marriage in

\footnotetext{
${ }^{1}$ These data are based on the $17 \%$ of Indonesian women aged between 20 and 24 years old in 2012.
} 
Indonesia. The case is especially interesting because while $I C O$ was deeply concerned about the effects of child marriage in the country, it did not feel able to dissent openly against it. The organization worked closely with the Indonesian government and religious leaders to promote the welfare of young people across a range of issues including education, health and nutrition. If ICO spoke out publicly against child marriage, the risk was that its other initiatives would be adversely affected, or even that the organization would be expelled from the country. Thus, by openly contesting child marriage, $I C O$ might endanger the welfare of the very children it existed to help.

These circumstances present a critical organizational problem that has seldom been systematically explored in the literature: how can organizations challenge guarded institutions when they are unable or unwilling to advocate publicly against them?

We position our study at the intersection of institutional theory and research on nongovernmental organizations (NGOs). In institutional theory, a burgeoning body of work has examined the strategies that organizations can use to contest prevailing institutional arrangements. These include constructing alternative ways of organizing through discursive and symbolic work (e.g., Lawrence \& Phillips, 2019) and convening events to debate new practices (e.g., Schuessler, Rueling, \& Wittneben, 2014). In the context of guarded institutions, however, such overt contestation is likely to be met with chronic resistance from elites with the authority to deny, or at least limit, the opportunities for organizations to make change. Thus, the strategies highlighted in existing institutional research may not be viable.

The literature on NGOs and other advocacy organizations has identified a range of actors, such as Human Rights Watch and Amnesty International, that are willing to counter resistance from local elites and to openly challenge guarded institutions (Spires, 2011; Thomas, 2001; 
Yaziji \& Doh, 2009). Contestation and activism lie at the core of these organizations, and existing research offers compelling accounts of how they mobilize partners, often civil society, social movements and grassroots activists, to oppose authority (Ndegwa, 1996; Reinecke \& Donaghey, 2015; see also, Vaccaro \& Palazzo, 2015; Rao \& Dutta, 2012).

However, for those organizations that rely - directly or indirectly - on the support of incumbent elites to fulfil their missions, openly undermining guarded institutions in this way can be risky and counterproductive: there are examples of high-profile organizations that have been ejected from the countries they operated in for speaking out against local practices and traditions (e.g., Reuters, 2018; Zeccola, 2011), and many more examples of organizations whose activities have been deliberately hampered or curtailed as 'punishment' for what guardians viewed as interference. Organizations such as ICO that are bound - legally or by convention - to political and religious neutrality, are part of transnational networks that need to maintain good relations with governments, and have other ongoing projects with local actors that they do not want to jeopardize, are especially vulnerable.

In our study, ICO overcame this dilemma by pursuing a different approach that involved advocating for change covertly. First, it assumed an alternative persona by disguising itself as a grassroots social movement. This involved working with partner organizations, as well as student groups who became the public face, so that its efforts appeared to emanate from grassroots activists when they were actually strategically orchestrated. Then, in a second step designed to stoke anger among the Indonesian public, $I C O$ used its disguise to create a disruption through a "high stakes event" (Schuessler et al., 2014) ${ }^{2}$ - in our case, the announcement of the outcome of

\footnotetext{
${ }^{2}$ According to Schuessler et al. (2014), "regular events" are characterized by routine interactions and modest outcomes which have limited effects on institutional dynamics. "High stakes events" are characterized by complex interactions underpinned by high expectations, with the potential for institutional change.
} 
a judicial review of child marriage in Indonesia's Constitutional Court (CC). Intriguingly, while the judicial review failed - the court upheld the current marriage law - the actual event, i.e., the public announcement of the judges' verdict, elicited public outrage from which 'real', independently organized grassroots activism emerged, and reform started to unfold.

We abstract from our findings, and the resulting process model, to make two key contributions. First, we develop a theorized account of how organizations can challenge guarded institutions when the risks are deemed too high to speak out publicly - an important, and widespread, organizational problem that has received scant attention in the literature. Our model suggests two strategies: the crafting of an alter ego that takes the appearance of a social movement that has emanated from the grassroots but is actually highly organized; and the use of this alter ego to incubate public dissent by means of a high-stakes event. We build on these insights to make an important second contribution. Specifically, we challenge the theoretical distinction that has been drawn in social movement theory between the organizational mobilization of activists - often referred to as astroturfing (Walker, 2014) - and seemingly organic mobilization that is said to emerge at the grassroots (Snow \& Soule, 2010). By contrast, we find that when an organization mimics the appearance of grassroots groups, it can stimulate grassroots activism covertly. This collective action can then take on a life of its own, with growing numbers of activists operating independently of the organization that helped to spawn it. The implication is that astroturfing and grassroots activism exist on a continuum and that the boundaries between them may be blurred.

\section{THEORETICAL BACKGROUND}

\section{Organizations and Institutional Change}

Organizations play a critical role in shaping institutions. This is certainly not a new insight, but with increasing attention on seemingly intractable "grand challenges" (George, Howard- 
Grenville, Joshi, \& Tihanyi, 2016), organizations' capacity to foster institutional change that alleviates deep-rooted social problems has been brought into sharp relief (Amis, Munir, \& Mair, 2017). Interestingly, the existing literature has focused mainly on organizational efforts to challenge, disrupt, and transform institutions openly - often in collaboration with incumbent elites. This research emphasizes the discursive and symbolic work that challenger organizations can enact to persuade others that a given institutional arrangement should be organized differently (e.g., Cornelissen, Durand, Fiss, Lammers, \& Vaara, 2015; Lawrence \& Phillips, 2019; Suddaby \& Greenwood, 2005). Another strand of literature considers the role of events "temporary social organizations" (Lampel \& Meyer, 2008: 1026) - in which diverse actors who do not habitually interact come together at a specific time and place to debate an issue of concern (e.g., Hardy \& Maguire, 2010; Mair \& Hehenberger, 2014; Schuessler et al., 2014).

However, building on the critique that resistance, power, and conflict have tended to be overlooked in studies of institutional change (Lawrence \& Buchanan, 2017), it is evident that some institutions cannot easily be challenged openly or directly. For example, Mair, Wolf and Seelos (2016) showed that the NGO Gram Vikas was ostensibly concerned with supporting communities through water and sanitation programs for villagers, but that its fundamental goal, which was concealed from local communities, was actually to transform deeply entrenched patterns of social inequality that were resistant to change. The need to use such alternative, covert strategies may be heightened in the context of repressive institutions where elites have the power to silence opposition. Here, the strategies highlighted in the literature may be ineffective or simply unavailable. For example, organizations cannot openly theorize alternative practices (Zietsma \& Lawrence, 2010), create shared discursive spaces (Hardy \& Maguire, 2010), or engage in "backstage convening" with opponents (Mair \& Hehenberger, 2014). Moreover, they 
may be unable to arrange events where common agreement is brokered (Schuessler et al., 2014), or bargain, persuade, and ally with insiders to negotiate change (Levy \& Scully, 2007).

In this paper, we focus on a particular type of repressive institution, which we term a guarded institution, that is extremely resistant to change. We conceptualize guarded institutions as defined by two characteristics: 1) their core practices are not only morally accepted but widely deemed as sacrosanct - those affected by them may not therefore feel they are being exploited and may view them positively; and 2) their core practices are actively and coercively protected by powerful elites who are deeply invested in maintaining the status quo. As such, guarded institutions present challenger organizations with two distinct barriers to change. First, they are required to question long-standing norms that many people deem morally appropriate and even virtuous. Second, they need to argue against - indeed to explicitly contradict - authoritative guardians who may not be afraid to use repressive means to suppress dissent and defend the institution.

\section{Challenging Guarded Institutions}

The role of organizations in challenging repressive institutions has tended to be overlooked in institutional theory. Notable exceptions include Vaccaro and Palazzo (2015), who studied how a group of grassroots activists in Sicily created an anti-mafia organization - Addiopizzo - to challenge the institution of pizzo, which is the practice of protection payments to the Mafia. Addiopizzo was able to change the meaning that key stakeholders attached to pizzo by reframing core values in Sicilian society - such as dignity, solidarity and community. This enabled the organization to promote an alternative set of practices, which undermined pizzo and indeed the "Mafia regime" more broadly, even though the challengers operated in a social context dominated by the fear of violence (see also Lee, Ramus, \& Vaccaro, 2018). In another important study, Rao and Dutta (2012) studied the mutinies of Indian regiments that formed part of the East 
India Company's Bengal Native Army in 1857. They show how challengers took advantage of "free spaces" that were insulated from the control of elites - the British army and colonial authorities - to force change despite the threat of death by hanging or firing squad.

Outside of institutional theory, the ways in which organizations can challenge repressive institutions has attracted more attention, with research on NGOs and other advocacy organizations such as inter-governmental organizations (IGOs), social movement organizations (SMOs), and labor unions providing especially important insights. Indeed, there is a growing body of research that examines how such organizations engage governments and other elites, with particular emphasis on their role as "watchdogs" vis-à-vis powerful actors (Baur \& Schmitz, 2012: 9; see also Doh \& Guay, 2006; Mercer, 2002; Scherer \& Palazzo, 2011; Spires, 2011;Yaziji \& Doh, 2009). These studies emphasize the limits of organizations' ability to effect social change when acting in isolation, and point instead to the importance of collaboration between organizations with overlapping goals (Gray \& Purdy, 2018). This finding comes through especially strongly in research on social movements, which has shown that the involvement of multiple partners - including grassroots activists and civil society - plays a key role in enabling organizations to address issues that they are unable to tackle alone (e.g., Staggenborg, 2010; Wang \& Soule, 2012; Zald \& McCarthy, 1979).

Crucially, such partnerships may shield organizations from the local elites that police repressive institutions because they allow challengers to "mobilize others and use social movement strategies to gain a seat at the negotiating table" (Gray \& Purdy, 2018: 198). For example, research has examined how the grassroots mobilizing of NGOs working in Nairobi slums empowered local community organizations to engage with the government in order to advance democracy in Kenya (Ndegwa, 1996). Similarly, studies of social change in Brazil have 
shown that from the late 1970s NGOs and SMOs played a key role in galvanizing civil society organizations and activists intent upon holding international financial institutions to account (Garrison, 2000). Other work has explored how the trade union movement joined forces with civil society in Bangladesh to promote workers' rights in the face of coercive resistance from government and local corporations (Reinecke \& Donaghey, 2015).

This body of scholarship has extended significantly our understanding of the role of NGOs and other advocacy organizations in repressive contexts. However, in seeking to apply these insights to our case, a close reading of the literature exposes an important shortcoming: not every organization has the same capacity to mobilize against local authority when seeking to challenge guarded institutions. Importantly, much of the literature examines advocacy NGOs that have an explicit mandate to challenge the status quo (e.g., Thomas, 2001) or organizations with close ties to social movements and grassroots activists (e.g., Spires, 2011; Ndegwa, 1996). In both cases, this work presupposes organizations' willingness to question prevailing institutions openly, as well as the ability to engage with and help mobilize grassroots activism. But many organizations seeking to make social change are "frequently required to refrain from activities defined broadly to be political" (Gershman \& Allen, 2006: 42), with those deemed by local elites as a threat to existing authority structures potentially subject to severe sanctions. Moreover, such organizations often lack the local relationships and legitimacy required to engage with social movements and activists at the grassroots (Collingwood \& Logister, 2005).

The complex relationship between challenger organizations and elites in repressive environments is illustrated, for example, in Zimbabwe where the law prohibits organizations with foreign funding from engaging in "political governance issues" (Kamete, 2009: 91). Similarly, non-profits in Ethiopia are closely regulated by the state, particularly when working 
with international partners, with authorities especially attentive to activity designed to promote human rights (Lang, 2013). And in countries such as China, Russia, Pakistan, Sudan, Turkey, and Indonesia, amongst others, organizations' advocacy work is tightly surveilled: international human rights organizations and local civil society organizations with foreign support are frequently forced to leave the country or close (Karim, 2016). In some of these cases, campaigns designed to discredit organizations have shifted to even more sinister efforts to criminalize political action (Brechenmacher, 2017). These tactics of intimidation are designed to serve as a warning to other organizations (Banks, Hulme, \& Edwards, 2015).

Being identified as a challenger to authority is particularly problematic for organizations that are bound to contracts of neutrality, organizations that engage in ongoing service delivery projects for which they need the support of local elites, as well as organizations that are unable to absorb the risks of operating in a repressive regime. In the context of guarded institutions, the number of organizations willing to be recognized publicly as challengers might therefore be especially low: the ability of guardians to suppress dissent by coercively "ruling in" and "ruling out" particular ways of talking and acting (Fairclough, 1992; Hall, 1997) makes any intervention a risky and demanding undertaking.

In sum, while institutional theorists have generated important insights into how organizations can challenge institutions, they tend to assume that organizations can do so publicly, and often in collaboration with actors who are open to reform. From the literature on NGOs and other advocacy organizations, we know how particular types of mobilizing organizations can enable change in the face of repressive opposition through direct action or campaigning alongside grassroots actors and social movements. What we know little about, however, is how organizations may drive change in repressive contexts when they cannot openly 
mobilize dissent or contest authority. Motivated to shed light on an alternative set of strategies in such circumstances, we examine how organizations can challenge guarded institutions when they are unable or unwilling to advocate publicly against them.

\section{METHODS}

\section{Empirical Context: ICO and Child Marriage in Indonesia}

ICO is an ideal case of an organization that is unable to challenge authority publicly. In

Indonesia, it is contractually obligated to remain politically and religiously neutral, and is dependent on the continued support of the country's leadership for a range of projects. These projects include initiatives to address child malnourishment in rural regions and improve social welfare services for children throughout the country. If $I C O$ had spoken out, it risked losing ongoing government support for these projects and, in the worst case, being expelled from Indonesia. Moreover, ICO's global headquarters are located in the West and the organization is funded mainly by donors in the West. As a result, openly questioning Islamic leaders' teachings on child marriage was especially risky for $I C O$ in Indonesia:

Child marriage is a sensitive issue. You may really run into big problems with powerful religious groups. And to avoid this problem right at the beginning, we took it really low profile. (ICO)

Our analysis of archival material and interviews with Islamic scholars (see Table 1) substantiated ICO's concerns. We identified two factors that limited historical opportunities for reform. First, child marriage has long been highly institutionalized in Indonesia - a legally accepted practice, with the marriage law anchored in the "symbolic importance of the Qur'anic passage that allows it" (Lev, 1996: 193). In our interviews, marriage was frequently described as a form of family insurance and as a way to avoid social shaming, and so many children were placed under pressure to get married as early as possible. Moreover, marriage was often considered the only legitimate way to be in a relationship and the only circumstance in which sex was acceptable.

Second, the institution is guarded by key religious leaders in the country and rooted in a 
particular interpretation of Islamic law ${ }^{3}$ (Katz \& Katz, 1975). While the marriage law of 1974 stipulates a minimum age of 16 for girls and 19 for boys, it allows these age barriers to be revoked by means of an official dispensation from an 'appropriate' authority, i.e., the Religious Court or a government officer. This makes it legal for men to marry girls before they graduate elementary school. One of the main factors upholding the legality of child marriage is the repeated release of fatwas $^{4}$ suggesting that "underage marriages are acceptable as long as the purpose of such unions is to build a happy family" (Fatwa N, 2010). These fatwas, though they are not legally binding, are highly regarded rulings by respected and qualified $M u f t i s^{5}$ and therefore carry significant weight (Hosen, 2008; Salim, 2007). Because family and marriage law in Indonesia are historically religious affairs (e.g., Butt, 2010), most fatwas concerning marriage are rooted in 'evidence' from the Qur' $a n^{6}$ or the Hadiths ${ }^{7}$. Corroborating that "sacred Islamic verses or regulations do not stipulate a minimum age" (Fatwa N, 2010), some religious groups use the justification that "Prophet Muhammad married Aisha when she was six years old and consummated the marriage when she turned nine (Sahih Bukhari 7:62:64) ${ }^{8 \%}$ and highlight passages from the Qur'an to demonstrate that the permissibility of "early marriages" should be evaluated not on the basis of age but rather the onset of a girl's sexual maturity (baligh).

Recent decades have seen increasing attempts on the part of the state to limit the role of Islamic law within a national legal framework (e.g., Assyaukanie, 2009; Bowen, 2003), which

\footnotetext{
${ }^{3}$ It is important to highlight that many Muslims in Indonesia and elsewhere - including parts of the Indonesian establishment - do not accept this interpretation, believe child marriage to be unacceptable, and campaign vociferously against it (e.g., Jones, Hull, \& Mohamad, 2011).

${ }^{4}$ Or ruling; non-legally binding opinions based on Islamic legal norms (e.g., forbidding cigarettes or homosexuality).

${ }^{5}$ Experts in Islamic law qualified to give authoritative legal opinions (fatwas).

${ }^{6}$ Literally means "the recitation;" central religious text of Islam.

7 Teachings of Prophet Muhammad.

${ }^{8}$ Passage of the hadith collections; there is significant disagreement among Islamic leaders and scholars as to how these passages should be interpreted and applied in Indonesia today (Butt, 2010).
} 
has led to concerns among conservative groups that they might "wither[...] into insignificance" (Butt: 2010: 287; Lev, 1996). Religious leaders have responded with efforts designed to ensure that family and marriage law "remain essentially Islamic" (Butt, 2008: 267). These dynamics reflect the wider power struggle over the place of religion within Indonesia's secular state system and make child marriage an acutely sensitive practice for both defenders and challengers.

In 2013, ICO decided to challenge child marriage despite the risks associated with doing so. Inside the organization, the decision was justified by the scale of the practice and its consequences. Indeed, the number of child brides - 340,000 each year - ranks Indonesia in the top ten countries with the highest absolute numbers of child brides in the world. In the broader region of East Asia and the Pacific, it is estimated that about $16 \%$ of women are married before they reach age 18 , representing $25 \%$ of child brides globally (UNFPA, 2012). The practice not only violates the UN Convention on the Rights of the Child ratified by Indonesia in 1990, but also has profound implications for children's health and life chances: it affects girls' educational attainment and substantially increases the likelihood of maternal mortality, HIV/Aids, reproductive health issues, trafficking and sexual violence (Bunting, 2005; UNFPA, 2012).

By hiding behind what appeared to be an authentic social movement, but was in fact a coalition of like-minded organizations (which we termed "the coalition"), ICO led a campaign culminating in a judicial review that challenged child marriage by demanding Indonesia's Constitutional Court (CC) amend the 1974 marriage law to exclude children under the age of 18. After the hearings, the country's highest judges announced the verdict: they rejected the request - an event that became one of high stakes because of the public outrage it triggered. For an overview of our research context, see Figure 1.

-Insert Figure 1 about here-

\section{Research Design}


We explore how ICO challenged the institution of child marriage in Indonesia through a qualitative, longitudinal case study. Our empirical focus represents a particularly revelatory case (Siggelkow, 2007), because it is concerned with an institution whose foundations are deeply anchored in the long-standing cultural and religious traditions of a country with the world's largest Muslim population. It is also a case of an "intractable conflict" (Brummans et al., 2008) where fundamentally different worldviews and conceptions of morality are exposed: for many in the religious establishment, child marriage is an appropriate response to the 'problems' of sex outside marriage and the breakdown of 'family values'; for the institution's challengers, it is a morally abhorrent practice that ruthlessly exploits vulnerable girls.

\section{Data Collection Process}

Our study includes interview, observation, and archival data that span 45 years from 1974 until 2019. We became aware of ICO's efforts against child marriage in 2014 as both authors were working with ICO on a related project. The data are concentrated around a two-year period, from when $I C O$ began to campaign against child marriage in Indonesia in late 2013 until after the Constitutional Court verdict in June 2015. We selected data that allowed us to explore our case by both "following forward" and "tracing back" (Langley \& Tsoukas, 2010: 11-12).

The first stage of data collection took place between January and July 2015. During this stage, we conducted eight initial interviews via Skype (mainly with $I C O$ ) and gathered news reports and archival data on marriage law, the role of religion, and issues of child protection in Indonesia. In the second stage, from July until September 2015, one of the authors travelled to ICO's global HQ for one week, followed by fieldwork in Indonesia for six weeks. During this period, she conducted face-to-face interviews with informants from ICO HQ and ICO Indonesia and its partners, engaged in observations, and collected archival documents. The aim was to learn about the efforts of $I C O$, local NGOs, activists, and lawyers to form a cohesive coalition of 
organizations - or "movement" as they had begun to call it. During a third stage, between October 2015 and June 2017, we conducted several follow-up interviews via Skype and collected additional archival data to seek clarification over conflicting accounts or interpretations among informants. During a fourth stage, between July 2017 and August 2017, the first author re-visited informants in Jakarta to learn more about the actors' activities after the initial coalition had dissolved. She also conducted fieldwork on Lombok - one of the regions where the judicial review verdict had sparked a local initiative against child marriage - to learn more about the effects of the verdict at the village level. During this stage, we also tried to speak with informants who would allow us to deepen our understanding of the religious and cultural rationales in favor of child marriage but had only limited success - the people who the first author approached were unwilling to talk openly to her. We therefore initiated a fifth stage of data collection in October 2017 during which we hired two research assistants (a law student in Jakarta and a college student on Lombok) to conduct six face-to-face interviews with religious leaders and local politicians on our behalf. In March 2019, for the purpose of clarification, the first author conducted four follow-up interviews with an ICO member, one of its partner organizations, and a former child bride and her husband. Table 1 summarizes our data sources. -Insert Table 1 about here-

Interviews. Our primary source of data is 105 interviews, 96 of which we conducted ourselves (74 face-to-face; 22 via Skype), 6 of which were conducted by local research assistants (all face-to-face), and 3 of which we sourced from ICO HQ archives. Informants included ICO members (50), members of local NGOs (30), local politicians (9), Islamic scholars/Imams (7), activists involved in StopChildMarriage (6), and a former child bride and her husband who now campaign against child marriage (3). Our initial point of contact was the executive office at ICO 
HQ, which referred us to ICO Indonesia, whose members helped us establish links to their partners in Jakarta. In Indonesia, the first author used "snowballing" (Flick, 2009) to identify other relevant interviewees. This allowed us to access a wide range of actors and helped identify those without immediate ties to ICO, such as student activists (see Figure 2).

We asked interviewees to reflect on their own and their organizations' involvement in the campaign against child marriage in Indonesia, focusing on their role leading up to the CC event, their reactions following the event, and their relationships and interactions with other members of StopChildMarriage. Interviews lasted between 20 minutes and 3 hours. On Lombok, a local translator accompanied the first author. She was important both for the literal translation and its cultural interpretation. We recorded and transcribed 81 interviews. For interviews with a translator, we engaged an Indonesian freelancer who transcribed both the English translation and (re-) translated the original words spoken in Bahasa Indonesia. Where informants asked not to be recorded, we took extensive notes in real time and typed them up within 24 hours. For the six interviews with religious leaders and politicians, we asked the research assistants to explore informants' views on 1) the religious and cultural justifications for child marriage and 2) the efforts against child marriage.

Observation. The first author visited ICO HQ for one week and their Indonesia office for six weeks, observing meetings, conferences, and events for a total of 90 hours in the summer of 2015. She conducted a second round of observations in the summer of 2017, visiting informants in their offices in Jakarta over four days and spending seven days with a partner organization that led an anti-child marriage program on the island Lombok. On the island, she followed staff into three different villages where the program operated, attended meetings with village and religious leaders, observed the protests of a youth group, and spent a day with a family where the wife had 
been forced into marrying her much older husband at the age of 16 (both now campaign against child marriage). Following standard procedures, she recorded these observations in a field diary.

Archival data. We collected 7,027 pages of archival documents and 23 hours of visual material. We categorized and reviewed all documents (see Table 1). The visual material included public debates and TV coverage related to child marriage. With regard to documentary material, we were fortunate to have privileged access to a wide range of sensitive documents provided by ICO HQ, ICO Indonesia, and ICO's partners. We also had access to agendas and minutes of all CC meetings and hearings. In addition, using Factiva, we traced newspaper articles about marriage in Indonesia as far back as 1993. Books, reports and academic articles helped shed further light on the topic before this date. We also used Google Trends to visualize the scale of public interest in child marriage from 2009-2019, summarized in Figure 3. -Insert Figure 3 about here-

\section{Data Analysis}

Analyzing the data was an iterative process. We moved between data collection, analysis, and existing literature to generate insights through four key analytical steps. Apart from the thick case description of Step 1, which was drafted by the first author, we analyzed the data conjointly.

Step 1: Develop thick case description. The first author developed a rich chronology of events and a narrative of how ICO mobilized against child marriage in Indonesia over time (Langley, 1999). Two key insights emerged that guided our subsequent analysis.

First, our initial interviews revealed that informants referred to their collective efforts as a "social movement" even though these efforts were strategically organized by $I C O$ and its partners. We therefore drew on the literature at the intersection of organization theory and social movement theory (e.g., Briscoe \& Gupta, 2016; Davis, Morrill, Rao, \& Soule, 2008; Weber \& King, 2013), including studies on different types of advocacy NGOs (e.g., Yaziji \& Doh, 2009) 
and Astroturf NGOs "which espouse a business agenda under the cover of NGO legitimacy" (Gray, Bebbington, \& Collison, 2006: 329), to guide our subsequent analysis.

Second, because our thick case description resembled a number of familiar concepts used in the studies mentioned above, we worked through a comprehensive list of concepts that could relate to our study, such as "collective action", "social movements", "campaigning" and "astroturfing." Collective action describes "all the ways in which people join their efforts in pursuit of common ends" (Tilly, 1978: 11). At the core of collective action is the idea that actors who are marginalized in some way - the grassroots (Castells, 1983) - protest dominant power structures or systems of authority to promote their collective interests. When grassroots activism becomes sufficiently coordinated, isolated acts of protests can become formalized as social movements, whose efforts "occur over longer time stretches, are driven by long-term goals, and develop formal organizations" (Rao, Morrill, \& Zald, 2000: 242; see also, Diani, 1992). Campaigning is a concept that has been ascribed to both social movements and organizations, and describes sustained collective claims making aimed at (social) change (e.g., Tilly, 2004). The fraudulent masquerading of organizations as social movements is referred to as astroturfing (e.g., Walker, 2014; 2016). Comparing our initial case description to these concepts and their definitions guided our data analysis and, later, helped us theorize our findings.

Step 2: Identify and corroborate key empirical periods with data. We used our case description to trace the changing contextual dynamics around child marriage in Indonesia and noted the transition from a guarded institution to one that became increasingly contested. We then looked for "critical junctures" (Sewell, 1996: 843), which allowed us to "temporally bracket" (Langley, 1999: 703) our research context's evolution into five periods: 1) before ICO mobilized against child marriage when contestation was repressed and activism scattered 
(Institutional Dynamics I, prior to 2013), 2) ICO's formation of a coalition of interested partners and organizations to campaign against child marriage (2013-2014),3) the emergence of public contestation (Institutional Dynamics II, end of 2013-2014), 4) the coalition's effort to organize a judicial review (2014-2015), and 5) the spreading of organic grassroots activism and open contestation after the review (Institutional Dynamics III, 2015-2019). While these five periods overlapped temporally, they were relevant analytically.

Step 3: Code data to develop core constructs. We focused our coding on the strategic actions of $I C O$ and its partners in periods 2 and 4 as we wanted to find out how they contributed to the changing contextual dynamics described in periods 1,3 , and 5. Specifically, we used NVivo to code phrases and terms to derive first-order codes. We then compared and contrasted first-order codes (Miles \& Huberman, 1994) which we collapsed into higher-level nodes and, with the help of relevant literature, refined to create more abstract conceptual categories, such as "masking" and "mimicking." A total of eight conceptual categories (second order codes) were identified ("layered co-optation", "uniting the discontented", "masking", "mimicking", "setting expectations", "moral confrontation", "proactive aggravation", "reactive amplification"). Finally, we identified relationships among the conceptual categories that might suggest theoretically distinct dimensions by iterating between empirical themes, conceptual categories, and theoretical dimensions. For example, the conceptual categories "masking" and "mimicking" were distilled into the theoretical dimension "feigning a social movement". The other three dimensions are "secretive coalition building", "provoking public outrage", and "fueling grassroots activism." Table 2 depicts our four aggregate theoretical dimensions and their empirical derivation.

Insert Table 2 about here-

Step 4: Develop theoretical model. To understand and evidence how the theoretical 
dimensions identified in Step 3 influenced the changing institutional dynamics we uncovered in Step 2, we relied on an approach to processual analysis as outlined by Pettigrew (1990, 1992, 1997). This helped us derive an integrated theoretical model, summarized in Figure 4.

We began by linking and aggregating our four theoretical dimensions, which we saw as representing two discrete strategies. We interpreted "secretive coalition building" and "feigning a social movement" as designed by ICO to hide its involvement and disguise its 'true' self so that it could challenge child marriage publicly. We thus labelled Strategy 1 "crafting an alter ego." With respect to Strategy 2, we interpreted "provoking public outrage" and "fueling grassroots activism" structured around a "high stakes event" (Schuessler et al., 2014), as designed to mobilize public opposition. We labelled Strategy 2 "incubating public dissent."

In theorizing the effects of these two strategies on the local context, we embedded and linked our conceptual categories to our macro-level data (e.g., news reports, Google Trends) (Pettigrew, 1997; Robinson, 2011). This allowed us to specify how ICO's efforts contributed to a shift in contextual dynamics over time; i.e., to unpack how Strategy 1 "increased interest in and awareness of the focal issue" (the first arrow in Figure 4), and how Strategy 2 "increased grassroots mobilization against the focal issue" (the second arrow in Figure 4). We refined the model several times, taking account of feedback from informants and colleagues.

\section{Ensuring Trustworthiness}

Both authors of this study were born and raised in Europe. Neither have close ties to Indonesia, and neither can claim to have been directly affected by child marriage. It is therefore crucial that we reflect carefully on our "positionality" in relation to our research context (Elie, 2006: 53). Studying phenomena that are culturally distant from researchers' own experiences might enable them to "see things not evident to insiders" (Merriam et al., 2001: 414), which can support the development of novel insights. At the same time, it poses the challenge of 
interpreting "the introspective meanings" that informants attach to particular behaviors and practices in a culture that researchers cannot fully comprehend (Merton, 1972: 41; see also England, 1994). Moreover, we are focused on an issue that has the potential to be difficult emotionally, which brings with it the challenge of researcher neutrality (Whiteman, 2010). This was a particular issue in our study, because the first author's motivation to embark on the project was rooted in a passionate belief that child marriage is a deeply exploitative practice.

To mitigate these challenges as best as we could, we took four steps to support the trustworthiness of our findings. First, one of the authors spent time in the field, both in Indonesia and ICO's HQ in the West, allowing her to glean important insights about the actors coordinating the campaign against child marriage (Lincoln \& Guba, 1985). She tried to familiarize herself with Indonesian culture as far as possible by, for example, discussing informally her emerging interpretations with the Indonesian family she stayed with in Jakarta. Combined with regular conversations between the authors (the second author was not in the field), these interactions also helped navigate the data's emotional content. Second, we triangulated multiple sources of data and interviewed diverse informants to help minimize the risk of retrospective rationalization (Eisenhardt, 1989). In doing so, we tried hard to understand the perspective of the religious and political leaders who supported 'early marriage' and collected extensive data about their justifications. Third, using a combination of real-time and archival data helped us build a robust case study over 43 years, reducing the risk of bias from any single perspective (Eisenhardt \& Graebner, 2007). Fourth, we repeatedly shared our thick description and emergent analysis with informants and colleagues (both from Europe and Indonesia) to augment the quality of our data analysis and the accuracy of our findings (Langley, 2007; Lincoln \& Guba, 1985). 
While we acknowledge that these steps cannot 'solve' the challenges outlined above, we have tried to be as reflexive, transparent, and authentic as possible in our approach to data collection and analysis (Lincoln \& Guba, 1985).

\section{THE CASE OF ICO AGAINST CHILD MARRIAGE IN INDONESIA}

\section{Institutional Dynamics I: Repressed Contestation, Scattered Activism (1974-2013)}

Religious leaders in Indonesia have long perceived opposition to child marriage as a threat to the legitimacy of Islamic law, and fiercely resisted change. On the one hand, their active protection of the institution limited the expression of injustice around which grassroots activism could organize. Sporadic attempts at dissent, such as the submission of a judicial review by a group of students in 2012, were quickly silenced and barely even picked up by the media. In fact, the 2012 judicial review received almost no public attention at all. Thus, grassroots activism prior to ICO's involvement in 2013 was scattered and largely ineffective (see Figure 1).

On the other hand, the sensitivity of the topic also made it risky for organizations to intervene, particularly foreign organizations such as $I C O$ that require good relations with the Indonesian authorities - the government "has the power to expel any international agency if it step[s] out of line" (Zeccola, 2011: 316) and has frequently exercised this power. Indeed, several

of our informants (including ICO members) recounted a story about Hope for Children [pseudonym], an international NGO whose Jakarta-based office was visited by the national intelligence agency after it had denounced child marriage in a local newspaper.

\section{Strategy 1: Crafting an Alter Ego (2013-2014)}

Eradicating child marriage was - and remains - one of the core priorities of ICO in Indonesia, but the difficult conditions outlined above meant that it had made limited progress on the issue. This was a source of deep frustration for $I C O$, which felt caught in a strategic bind: given the sensitivity of child marriage and the risks of overtly contesting the institution, ICO 
feared being identified as a source of dissent; at the same time, the importance that $I C O$ attached to the issue meant that it could not simply do nothing. Thus, early in 2013 a decision was taken by $I C O$ 's leadership in Indonesia to build a secret coalition of partners to support a renewed campaign against child marriage in the country. To minimize, as far as was possible, scrutiny from the religious establishment guarding the institution, the coalition then feigned a social movement i.e., it pretended that it was actually an authentic citizen collective that had emerged from the grassroots. Combined, these two activities allowed $I C O$ to craft an alter ego, i.e., to create a temporary shell organization that appeared to be grassroots-driven but really was part of a highly organized campaign led by ICO. While, in retrospect, these two activities appeared carefully planned, our informants described a more organic development. It was not until the media recognized StopChildMarriage as a grassroots group that ICO began to realize the benefits of hiding behind the appearance of an authentic social movement.

\section{Secretive Coalition Building}

Finding the 'right' partners for the coalition was a difficult, nonlinear process (cf., Vaccaro \& Palazzo, 2015). ICO decided that it needed to first spend time "listening" to identify actors that shared its perspective on child marriage. It learned that two women's rights groups had begun work on a judicial review to the $\mathrm{CC}$ requesting that the marriage law be amended. For ICO "there [was] no need to start from scratch and reinvent the wheel" (Interview \#4) and so focusing its efforts on a judicial review became part of its strategic agenda - a "pragmatic and opportunistic" decision (Follow-up e-mail, \#1), helped by the fact that $I C O$ 's earliest ally was the Association of Criminal Justice Lawyers (ACJL) [pseudonym] whose members were equipped to draft such a review. Above all, the focus on the judicial review was perceived as a useful way of making connections to partners that could take part in a broader initiative to challenge deeply held assumptions about child marriage. Our analysis suggests that this key task of building a 
secretive coalition involved (1) layered co-optation - carefully sounding out potential partners with shared aims and complementary skills, and (2) uniting the discontented by articulating a shared vision and goal that a diverse set of parties can rally around.

Layered co-optation. The existing activist groups that $I C O$ contacted had different values and ways of approaching the issue, some of which were not in line with their own ideas. Following negotiations between members, the coalition implemented a structure with four layers. It was agreed that $I C O$, supported by ACJL, would take the strategic lead, with the smaller organizations preferring to operate from the periphery. Our informants from local organizations reasoned that, should the coalition be targeted by the authorities, ICO was better placed to absorb any backlash given its size, resources, and reputation. In other words, layered co-optation was an organic process shaped by members' expertise and level of risk aversion. The layered structure of the coalition also reduced the potential for internal conflict because it afforded each member a specific role. See Figure 3 for a visual representation of the coalition's structure.

\section{-----------Insert Figure 3 about here----------}

This figure was derived from our fieldwork during which, in order to aid our own understanding, we asked actors to mark and describe their position in the campaign against child marriage on a 'map' indicating their connections to other members (primary connections are indicated by a grey line). Layer 1 represents the most active parties, Layer 4 the most peripheral contributors. Layer 1 consists of ICO Indonesia, a club of lawyers (ACJL), a local children's rights organization (LCRO), and three women's rights organizations (WR1, WR2, WR3). Layer 2 includes universities, research organizations (RO), a petitioning website (Change.org), a youth alliance (YA), a civil society organization (CSO), journalists, medical doctors, celebrities, and other women's rights organizations (WR4, WR5, WR6). Layer 3 represents the governmental agencies (GA1, GA2) in support of the first two layers. Their support was limited as their 
affiliation restricted their ability to protest against national law. Layer 4 consists of ICO HQ and ICO's global research center that contributed knowledge and other resources from abroad.

Uniting the discontented. With so many diverse groups and organizations becoming part of the coalition, ICO decided that it was important to continually reinforce their common goal: the eradication of child marriage in Indonesia. In achieving this goal, the core partners of Layer 1 agreed to focus on submitting the judicial review to raise the minimum age of marriage - an opportunity identified by $I C O$. With this aim in mind, they began to allocate specific tasks. Regular monthly meetings were held in neutral spaces such as coffee shops - rather than at the premises of core partners. This was a strategic decision by $I C O$, designed to make everyone feel as if they had an equal say. While the monthly meetings frequently exposed different opinions, overall, coordinating the coalition was smoother than expected. This may have been partly due to the absence of "logo wars", as a member of one of the organizations involved, explained:

We don't have that war of logos - we all have our own tasks and ways. So, we don't stand in the ways of each other... We have different agendas but then, don't we all want the same? That is, stop child marriage. Make things right. (Interview \#67)

Building a secretive coalition was mainly in the hands of $I C O$ and its core partners who were charged with organizing members into a cohesive team. When the coalition seemed to be operating relatively effectively, ICO turned its attention to finding ways of using its constituent expertise to challenge child marriage. Given the risks associated with being seen to do so publicly, it took the decision to organize its campaign under the guise of a social movement.

\section{Feigning a Social Movement}

$I C O$ was not the only organization to fear public association with child marriage. The decision to disguise as an organic social movement was strongly supported by the coalition members because it allowed the criticisms of child marriage to appear to emanate from 'the 
people'. Our analysis suggests that feigning a social movement involves two core tasks: (1) masking the identities of coalition members, (2) mimicking a 'real', locally based movement.

Masking. We define masking as the deliberate act of concealing partners' organizational affiliations. In our case, it meant that the core partners involved in the coalition did not identify themselves in the public domain; they constructed a mask behind which they conducted their activities. While not everyone involved in the coalition chose to hide in this way (e.g., members of WR1 and WR3 openly discussed their opposition to child marriage), most partners felt the need to do so. The mask, or the "face" as many interviewees called it, was designed to make the coalition's campaign appear as a grassroots movement. As one ICO member explained:

Child marriage is such a culturally sensitive topic. We decided it's better to send others to the front and then give them support without ourselves being visible. For us, it's a strategic question. We're an international organization and it's not well perceived to appear to be prescribing something 'from the outside'. (Interview \#15)

In order to "lead from behind" (Interview \#3), the core partners created an online platform run by a group they called StopChildMarriage and a physical frontline of students (members of YA) that were recruited by ICO and ACJL to speak on the coalition's behalf. Deliberately implying a group of young activists, the actors behind the digital face were presented as "a grassroots movement dedicated to increasing Indonesia's minimum age of marriage and strengthening law enforcement to end early and coerced marriages" (GNB, 2014). In reality, however, it was mainly the lawyers from ACJL who drafted the posts that appeared on StopChildMarriage's platform, but without their organizational affiliation ever surfacing. Similarly, whenever core members did speak to the media, meet with non-affiliated parties, or attend sessions on child marriage run by third parties, they removed any signs that could expose them as belonging to a particular organization. In the words of an ICO member: 
We are not showing our identity...When I go [to meetings], I give my personal ID card rather than my ICO ID cards... I remember one incidence where a major partner was called by the national intelligence office because of its child marriage campaign...so we avoid visibility. (Interview \#50)

Mimicking. StopChildMarriage also sought to build its legitimacy through a strategy of mimicking - adopting practices typically associated with grassroots activists. This involved two key elements: reframing the dominant cultural understanding of child marriage as promoted by the institution's guardians, and engaging in activities such as protesting, petitioning, and campaigning that closely resembled those performed by organic social movements.

The first of these elements - reframing - was far from straightforward: child marriage was deeply entrenched and taken-for-granted across large swathes of Indonesia. Journalists, policy makers, and government officials often perpetuated a narrow religious view, presenting child marriage as a "solution" to the stigma attached to unwanted pregnancies and as a way for girls to avoid becoming a perawan tua (literally "old virgin"). Indeed, these actors fastidiously avoided the term "child marriage", preferring the less emotive phrase "early marriage."

The aim of StopChildMarriage's reframing efforts was to "make the practice an issue" (Interview \#52). However, ICO and its partners were not themselves victims of child marriage they were acting on behalf of victims and were therefore unable to mobilize their own sense of injustice. Thus, they had to imagine, simulate, and interpret the trauma that they believed child brides suffered. As such, they sought to connect child marriage to other social problems, such as gender discrimination, mental health, educational attainment, and poverty. The diversity of actors involved in the coalition again proved useful because each was able to contribute different insights which could then be tailored in messages for diverse audiences. For instance, WR4, a Muslim feminist NGO, was able to connect to the Muslim communities it served. They were behind StopChildMarriage posts that questioned the Islamic rationale for child marriage, and shared messages such as the following: 
In Islam, it is haram to force your child to marry whom you want, as a parent. In fact, it is a great sin... forced marriages are not allowed in Islam!!...

Forced marriages are clearly not acceptable according to The Quran: $\mathrm{O}$ you who believe, it is not lawful for you to inherit the women by forcibly/unwillingly... [4:19]

Marriage is done by mutual agreement: And if you divorce the women, and they have reached their required interim period, then do not prevent/hinder them that they marry their partners if they mutually agree between themselves in a kind/equitable manner... [2:232]

...May Allah give us the ability to understand the sacred concept of marriage and the Islamic approach towards it. Amen. (SM Re-Post by ACJL, 2014)

ACJL, on the other hand, strongly emphasized the gender discrimination that they believed lay at the core of child marriage:

Child marriage is a human rights violation... Why should there by a difference in law between girls and boys?... Is there a difference between men and women so that there are different legal limits?... I understand this problem is very complicated and involves the question of religious dogma which may have expired for its interpretation... But in my heart, I write this as this is part of my effort to glorify women in the country I love. (SM Post by ACJL, 2014, translated from Bahasa)

Similarly, WR3 and WR2 illuminated the maternal health consequences, while WR1 emphasized the psychological effects. While significant effort went into this kind of bespoke communication, all members of the coalition continually used the label child marriage - rather than early marriage - in their messaging in an effort to underline the "reality" of the practice.

In addition, StopChildMarriage organized a range of grassroots-branded activities designed to reinforce the perception that it was a 'real' movement. The youth groups and university students that $I C O$ had recruited played a particularly important role in this regard. ICO worked directly with 12 student leaders. These student leaders then recruited other supporters - about 500 in total - that were part of their networks. The students engaged in protest marches and social media campaigns, drafted a change.org petition which by November 2015 had attracted 14,658 signatures, initiated "selfie-campaigns" encouraging young people to denounce child marriage, and set up information booths during Car-Free Days in Jakarta - just like a grassroots movement might have done. While the leaders of the youth and student groups knew ICO was 
behind StopChildMarriage, the students that they recruited (including the people who signed the change.org petition) did not. A student who was recruited by a friend in a student seminar unaware of ICO's role - tells the story of why he became involved as follows:

In the seminar, we talked about underage marriage, below 18 years old. We were told about the situation of child marriage in Indonesia. From then, and from this point on, actually, I found it terrible. There's a lot of child marriages happening... so we, from the medical faculty, of course, we just want to help fight this kind of thing because it's not good for the health of the child...they are not ready to marry... That's why I'm concerned. (Interview \#47)

As such, mimicking increasingly generated a momentum of its own. In order to keep the youth leaders engaged, $I C O$ sought to reinforce their growing emotional connection to the cause by "making the issue of child marriage a personal matter" (Interview \#58). The rationale was that the more strongly the students felt about child marriage, the more authentic their protests would become: this was critical, because these students acted as the movement's public face. As an example, an $I C O$ member gave us an account of how she sent a student to a children's hospital to identify expert witnesses to testify in court. While this task had an important practical objective, the motivational effects on this student were very evident:

...the more they learn about the issues, it becomes closer to their own personal cause... for example, in the search for an expert witness, one of our colleagues from StopChildMarriage had to go the hospital to interview some of the medical doctors. She found a girl who was 13 years old and about to give birth in the hospital...she came back to us and said, 'now this is becoming personal, I will make this end' because she saw herself there... (Interview \#4)

The process of feigning a social movement was an ongoing one, whereby masking and mimicking repeatedly fed into one another. While masking allowed the challengers to conceal their identities, mimicking allowed them to act as if they belonged to a grassroots movement that offered an alternative perspective on child marriage. Together, these actions enabled StopChildMarriage - which was in reality an ICO orchestrated campaign - to be perceived as an authentic citizens' collective by the general public and the media. This was evidenced, for example, by newspapers beginning to refer to it as a "group of concerned Indonesian citizens" 
(Public Social Media (SM) Post, 2014), a local "grassroots movement" (e.g., Asia-Pacific News, 2014) and later a "pioneer movement against child marriage" (Public SM Post, 2015).

Institutional Dynamics II: Emergent Contestation, Orchestrated Activism (End 2013-2014)

Intriguingly, the work of StopChildMarriage started to have important institutional effects. Specifically, it led to renewed interest in child marriage among many Indonesians who had hitherto accepted the institution in an unquestioning way, and it led to increased awareness that child marriage was an issue of deep concern for some in Indonesian society. The result was that child marriage in the country came to be characterized by emergent contestation. Many journalists drew explicitly upon the arguments against child marriage that StopChildMarriage had developed. For example, some referred to Indonesia's failure to meet the UN Millennium Development Goals and appealed to national pride with claims such as that "[child marriage] will not only endanger women's health but will also damage Indonesia, as a country and a nation" (Jakarta Post, 2014a). Other articles targeted the religious justifications for child marriage, discussing passages in the Qur'an and Hadiths frequently cited to support the claim that "the provision on the minimum age of 16 is consistent with Islamic teachings" (Indonesian Ulema Council (MUI), 2014), just as the members of StopChildMarriage had done.

The renewed public interest in child marriage subsequent to StopChildMarriage's activities is evidenced by Google Trends: the relative public interest in pernikahan anak (the Bahasa term for "child marriage" that StopChildMarriage used in its campaign) doubled with the surfacing of StopChildMarriage in public (see Figure 4, Box “Institutional Dynamics II").

StopChildMarriage's increased public visibility compelled several religious leaders to respond to accusations that child marriage was contested in Indonesia:

Deputy Minister of Religious Affairs [...] argues that not many women get married at the age of 16, even though protected by the law. "But if anyone wants to apply for judicial review, we'll let them," [he] said when contacted yesterday. (Тетро, 2013) 
However, the majority of religious leaders remained silent. For the more hardline members of the religious establishment, this may have been because they did not yet see StopChildMarriage as a significant threat, but also because they did not want to give it the oxygen of publicity. A YA member explained the silence of religious leaders as follows: "some say to us privately 'Oh, I'm actually on your side, but my organization is not...' so they say 'no' [when asked to comment]. They just want to be on the safe side with their supporters... it's political” (Interview \#85).

\section{Strategy 2: Incubating Public Dissent (2014-2015)}

The lack of engagement from conservative religious groups was acknowledged by StopChildMarriage members. ICO thus reasoned that they needed to create a "bang" (Interview \#4). To do so, they came to the view that they needed to motivate citizens to demand action through a sense of anger and injustice. Put differently, they needed to incubate public dissent around the issue of child marriage so that they would not be the only ones calling for change.

In the search for answers as to how this could be done, ICO and its coalition partners increasingly came to see the judicial review - viewed in Strategy 1 simply as a way to connect to likeminded actors - as presenting a unique opportunity. They believed that the likelihood of the judicial review being accepted was slim but hoped that the negative verdict would generate the kind of public outrage that would precipitate institutional change. Thus, a decision was taken to use the announcement of the judges' verdict as a focal point for protest that would allow the coalition - still hiding behind StopChildMarriage - to concentrate its efforts against child marriage and to generate as much publicity as possible from it, which could then be leveraged for maximum effect. An advantage of this approach, $I C O$ and its partners reasoned, was that the judges' announcement - if sufficiently noticed by the public - would force religious leaders to join the public discourse and to defend the indefensible by articulating their arguments in support 
of child marriage. If citizens felt strongly enough about the "misguided" and hypocritical anchoring of the practice in religious teachings, they would be more likely to act.

To incubate public dissent, the actors behind StopChildMarriage first sought to provoke public outrage by channeling the increased public interest in and awareness of child marriage onto an event (i.e., the CC's verdict). The aim was to arouse emotion so that the event became one of high stakes, which would then allow them to fuel grassroots activism.

\section{Provoking Public Outrage}

The judicial review was crafted by ACJL but officially filed by two activists (one of them a former child bride) who had joined StopChildMarriage upon the request of WR3. ICO reasoned that to make the judicial review verdict a high stakes event, they had to ensure that the judges' verdict was noticed. Specifically, our analysis suggests that provoking public outrage prior to an event comprises two components: (1) setting expectations and (2) moral confrontation.

Setting expectations. The majority of StopChildMarriage members expected the judicial review to fail due to the judges' composition of 8 Muslim men and 1 Catholic woman and their often politically motivated religious affinity (Interview \#8). Only ICO sought to ensure that StopChildMarriage's messages reached the CC judges in an effort to change their views:

With the lawyers' group, for example, we've been asking them 'what kind of newspapers do judges read?' Then we can write something in that particular newspaper and urge them to come up with their verdict more immediately [...] And then we try to find out, who are the influential people around him [i.e. Constitutional Court judge], and who can get to him, and influence him, one way or another. And that is often very informal. 'Oh, his wife went to school together with my friends....' So yes, we try that kind of approach as well. (Interview \#4)

However, the main focus of the coalition's expectation-setting efforts - including those of ICO - was the broader public. Members organized events at local universities, hosted journalist workshops and turned to channels such as radio to reach villages not included in the $28 \%$ of the Indonesian population with Internet access (Indonesia Statistics Portal, 2015). They also teamed 
up with other activist groups as well as with high-profile allies, including politicians, academics, and public figures, to prepare the public for the upcoming judicial review - captured in newspapers which said that the "group of activists [...] are optimistic they will win their case" (Jakarta Post, 2014b). Furthermore, the public protests that members of StopChildMarriage initiated became increasingly emotional as the announcement of the CC's decision got closer, culminating in a risky - and potentially dangerous - protest in front of the court during which a group of women led by a well-known Indonesian women's rights activist laid down flowers and banners, grieving at what they saw as the profound injustice of child marriage. These public displays of anger and despair just prior to the verdict contributed to the creation of public expectations and "hope that the Constitutional Court will make the right decision" (Public SM Post, 2015). It was also intended to increase pressure on the Court's judges.

Moral confrontation. Ultimately, setting public expectations for a positive verdict, combined with the belief of many members of StopChildMarriage that the judicial review would not succeed, appeared to play in their favor because it allowed some of them to start "planning for failure" (Interview \#8). Knowing that the main opposition to changes in the marriage law would come from religious groups and Islamic scholars, the coalition - especially ACJL and the Muslim feminists of WR4 - focused their energy on confronting these groups. For example, in January 2015, ACJL (still in the name of StopChildMarriage) posted on social media:

'Rather than seeing pornography and girls being tempted into doing premarital sex, it is better for them to be married. And particularly if the girl is pregnant, the only solution is marrying her off' [reciting/ridiculing religious arguments] ... whether she wants to or not, whether she is in love with the one who made her pregnant or raped her. In the case of the latter, instead of punishing the rapist, the girl gets punished by forcing her to enter into a marriage with her rapist.

Is that really a good enough reason to let the destiny of our daughters end this way? I think that would be the worst of the worst crime a parent could do... (SM Post by ACJL, 2015)

In the same vein, WR4 posted a number of page-long comments confronting the religious 
argument for child marriage in a very systematic way. Titled "forced marriages are not allowed in Islam!!" and concluding with "may Allah give us the ability to understand the sacred concept of marriage and the Islamic approach towards it", their posts drew attention to numerous passages in the Qur'an which say that marriage requires explicit consent from both parties, thereby undermining the idea that parents can give consent on their children's behalf.

Following the submission of the judicial review, and while the court hearings were taking place, ICO drafted a strategy to rebut the arguments in favor of child marriage from multiple angles. The hearings, which took place over the course of several months, provided a physical space for arguments from both sides to be exchanged and discussed: the plaintiffs and the Court's judges (as defendants of the law) were allowed to invite expert witnesses to provide evidence for their respective positions. StopChildMarriage members invited medical doctors, psychologists, students, and legal and human rights experts to testify. The judges invited representatives of Indonesia's officially accepted religions including Islam, Protestantism, Catholicism, Hinduism, Buddhism and Confucianism, as well as speakers of the two largest Muslim organizations, for their expert opinions.

It was apparent during the hearings that only the Islamic organizations were against the amendment of the law - despite many of their members voicing "behind-the-scenes" support for StopChildMarriage (Interview \#8, 29, 32, 68); all other expert witnesses were in favor.

\section{The Event (June 18, 2015)}

Consistent with the Islamic groups' recommendations, on June 18, 2015, the Indonesian CC rejected the request to adjust the law to protect children from underage marriage. The vote read $8: 1$ - the eight male judges voted against the law review, the only female judge voted in favor. The rationale of the $\mathrm{CC}$ was best captured by the words of one of the judges: 
Progress in areas such as nutrition and technology may speed up a child's sexual drive, which should be channelled through legal marriage as ruled by religion, so that a child is not born out of wedlock. (IB Times, 2015)

In the immediate aftermath of the verdict, and despite the anticipation of failure, members of StopChildMarriage - especially the youth groups - were upset about the outcome. However, with the passing of several days, the verdict came to be interpreted and portrayed as a "blessing" (Interviews \#58, 72) because it provided, as many members had hoped, a platform for protest: the verdict was heavily criticized in the following days and weeks. Specifically, the media ridiculed the religious argumentations, such as that "early marriage prevents free sex," "is part of Islamic ideology," and "protects children from pornography" (CC minutes, 2015). This type of coverage was a crucial stepping-stone for StopChildMarriage to exploit the event's outcome.

\section{Fueling Grassroots Activism}

The final theme in our analysis - fueling grassroots activism - is concerned with the actions of challengers in the event's immediate aftermath, actions designed to leverage the event's outcomes in a way consistent with their interests. This is a formidable undertaking because the outcomes of high stakes events are inherently unpredictable, which means the exploitation of public outrage cannot be planned in a detailed way. Specifically, we found that this involves the (1) proactive aggravation, and (2) reactive amplification of the event's outcomes.

Proactive aggravation. On and after June 18, in various social media blogs and online forums, comments like the following were commonly expressed:

Don't even start me on nikah sirih [Religious (often unregistered) marriage], by which senior religious figures can indulge themselves for a legal one-night stand with a 12-year old. And divorce her the next morning. I can handle the corruption here - it's total and all consuming - but this stinking hypocritical application of 'moral and religious values' just appalls me. (The Interpreter, 2015)

Many bloggers equated child marriage with "institutionalized paedophilia" and strongly condemned the judges' verdict as "reinforc[ing] the virtual state protection of paedophiles" 
(Public SM Post, 2015). Various newspapers, including the China Post, Jakarta Post, and Human Rights Watch wrote about Indonesia's failure to protect children from sexual violence, abuse, and maternal death, accusing the judges of jeopardizing girls' life chances. StopChildMarriage's members capitalized on these strong emotional reactions, and equally strong reactions by many members of the public, by fueling the emergent grassroots dissent with their own articles.

Interestingly, we observed that the actors involved in StopChildMarriage began to operate as individual entities again, with each party leveraging the event's outcomes according to their goals. For instance, ICO started publishing personal stories of child brides through its own media channels, and placed child marriage at the center of its 5-year strategy in Indonesia; YA used the platform to organize a separate youth-led campaign against child marriage; WR5, WR3, WR2, and WR1 outed themselves as members of StopChildMarriage, receiving plaudits for their efforts. In other words, the loss in the CC became a "tremendous success story" (Interview \#72) for many of the actors involved - their articles and public statements generated thousands of comments across multiple media platforms. One of the $I C O$-authored articles, published in the highest profile Indonesian newspaper, became the most read article on the day of its publication, viewed over 105,000 times and shared more than 11,000 times in just 24 hours. It is important to note, however, that not everyone saw the result as a "victory". For the lawyers, for instance, failing in court was perceived as a setback despite the attention generated.

Reactive amplification. Not all of the positive outcomes were intended. For example, and somewhat unexpectedly, regional governments amended local policies, academics and other high-profile individuals took a stance against child marriage, and organizations and individual activists wanted to become part of the movement's efforts. An informant from the lawyers' club, which received the emails and messages addressed to StopChildMarriage, noted: 
It's quite funny because after the judicial review, after the court ruling not in favor of our petition, there is a lot of "experts" that appeared suddenly out of nowhere. Where were these people before? (Interview \#63)

The members were contacted by activists and organizations from many countries with offers of support. Where possible, they engaged with these unintended consequences in order to amplify their impact. Sometimes this involved forging new partnerships, but for the most part these outcomes allowed the key actors behind StopChildMarriage to pursue their own paths again.

Depending on their individual plans, several organizations fully unmasked, i.e., exposed themselves as having been members of StopChildMarriage, while others kept their involvement a secret. YA and several of the women's rights organizations, for example, leveraged their affiliations with StopChildMarriage as the pioneer 'movement' to legitimate their own child marriage initiatives. Actors who planned to work with the government and/or religious groups, on the other hand, were not keen to be associated with StopChildMarriage. For instance, ACJL was considering another judicial review; ICO intended to collaborate with the government and, ironically, several of the Islamic groups that had opposed them in court, on a strategy for how to achieve the UN Sustainable Development Goals; WR4, the religious feminist NGO, began collaborating closely with communities where child marriage was especially prevalent.

While, at the time of writing, the set of actors that were behind StopChildMarriage have no specific plans to re-unite, StopChildMarriage's virtual platform was adopted by a larger, global partnership of civil society groups and is now formally run by WR3.

\section{Institutional Dynamics III: Open Contestation, Grassroots Activism (2015-2019)}

Our data suggest that the strategic actions that StopChildMarriage members performed in Strategy 2 had a significant effect. Specifically, we identified two key changes in our focal institutional context linked directly to StopChildMarriage: the increasingly open contestation of child marriage as an issue, and the emergence of 'real' grassroots activism. 
With regard to the nature of contestation, we noted an earlier shift (Institutional Dynamics II) from "repressed contestation" to "emergent contestation" as awareness of and interest in child marriage increased. By converting this awareness and interest into outrage, however, another major shift occurred: the issue of child marriage became openly contested. According to our interviewees, one of the main effects of the verdict and its aftermath was to break the barrier of fear and intimidation that had hindered contestation prior to the judicial review.

The feeling of safety supported a marked change in the discourse around child marriage. This was particularly evident in data from several children's organizations, which reported that their social media platforms were liked, shared, and commented on by significantly more people than at any point prior to the verdict (e.g., RK, 2015). Indeed, according to Google Trends, interest in the topic of "child marriage" (Bahasa: pernikahan anak) in Indonesia spiked significantly after the verdict and was much higher than the equivalent period following the previous judicial review in 2012 (see Figure 4, Box “Institutional Dynamics III”).

The second key change to the institutional context, which follows on from the first, is the emergence of grassroots activism. While the link between the advent of this activism and StopChildMarriage was not always clear-cut in our data, we were able to identify several specific instances where we could draw direct connections between the two. For example, a Jakarta-based group of law students was motivated by the CC's verdict to travel to rural villages to talk to people about "how we can encourage them to send their children to college, talking about living in the city, talking about the law" (Interview \#47). In Semarang, Central Java, a group of peaceful protestors, who portrayed itself as a continuation of StopChildMarriage and eventually connected to WR3, took to the streets with the message that "child marriage was one of the most untouchable methods of operations of sexual violence against children" (Jakarta 
Post, 2016) and demanded government action. Similar grassroots efforts sparked in other regions of Indonesia, including Tangerang, Kebumen, West Nusa Tenggara (incl. Lombok), and Bali.

In another significant twist, in April of 2017 three child bride survivors followed up on StopChildMarriage's attempt to change the marriage law in the $\mathrm{CC}$ by submitting their own judicial review. This time, they had grassroots support and national politicians, including the only slightly changed lineup of - Constitutional Court judges ${ }^{9}$. Indeed, in December of 2018, in a surprising ruling - one with the potential to "pave the way for the elimination of rampant child marriage in Indonesia" (Jakarta Post, 2018) - the CC judges ruled the existing marriage law to be unconstitutional and ordered lawmakers to revise it: a very different outcome than that of the previous judicial review that $I C O$ had supported. A lawyer of ACJL commented as follows:

The petitioners were connected to WR3 and were survivors of child marriage. In our capacity as lawyers, we helped them collect evidence and to prove their legal standing...

Basically, judges ruled that the article in the marriage law is unconstitutional, and that they understand that the minimum age must be raised. They ordered the Parliament and the President to revise the law. And if they fail to do so by 2021, the age barriers will be automatically raised to age $18 \ldots$ This ruling is surprising and very rare... in the last 5 years, you cannot find a single case where something like that happened, that they first reject and now order a law revision.

...How we contributed? I think after we lost our case with ICO - or StopChildMarriage - the media and the public began to understand the danger of child marriage. Almost every month after we lost the case, there was a major newspaper who wrote about child marriage. This is unprecedented... so that shifted the momentum and made it a very different context for the Constitutional Court to this time. So, our 'failure' really wasn't one after all. (Follow-up email \#11)

Given their connection to the petitioners, WR3 and ACJL were asked to help draft the revisions of the law for the Parliament. Whether the law will be changed, and if so when that will happen, is yet to be seen.

Many conservative religious groups did not agree with the $\mathrm{CC}$ decision and remained hostile. However, we also saw fractures in the religious establishment begin to emerge. Several

\footnotetext{
${ }^{9}$ Seven of the CC judges were serving when it handed down the 2015 decision. Only two judges were replaced.
} 
religious leaders agreed to participate in open debates about child marriage at high-profile conferences such as the World Youth Foundation and International Women's Day. More surprisingly, some even took a public stance by, for example, encouraging regional governments to pass their own anti-child marriage laws or by joining the "Child Friendly City/District Initiative", a UN project designed to protect the rights of children.

One of the most remarkable developments from the perspective of our informants was the emergence of a group of female Islamic clerics (the Indonesian KUPI Women's Ulama Congress) that declared an unprecedented and "rare fatwa against child marriage" $(B B C, 2017)$ in April of 2017, in which they urged the government to raise the legal age of marriage for women. In their ruling, the female clerics explicitly referred to StopChildMarriage and cited the studies its members had put forth in court. Fatwas (see footnote 6) are non-legally binding rulings that are usually issued by the highest religious authority, the Ulama Council, typically adjudicated by men. As the first major meeting of women clerics, the female Ulama was deeply controversial and denounced by conservative Islamic leaders.

Finally, the renewed interest in the 'injustice' of child marriage did not go unnoticed in the international community (e.g., The Economist, 2016). Indeed, the attention generated helped to unlock a new influx of funding for child marriage initiatives in Indonesia, including one that the first author visited on Lombok. While those leading this initiative did not know who the original actors behind StopChildMarriage had been, they credited the group for having legitimated the fight against child marriage - allowing them to benefit from new financial resources and a recently forged collaboration with a major international NGO. Thus, the public outrage following the $\mathrm{CC}$ verdict created new opportunities for challengers to the institution.

\section{Alternative Explanations}


Two plausible rival explanations to our interpretation of the case are that the effects we observed occurred not because of the ICO-led campaign but (1) because the institutional context was already changing due to shifting public attitudes and would have happened anyway, or (2) because of interventions on the part of other actors. However, several pieces of evidence mitigate against these alternatives. With regard to the first, our analysis of archival documents as well as our interviews with local informants who had opposed child marriage long before they joined ICO's campaign strongly suggest that the institution of child marriage was largely static prior to ICO's involvement. With regard to the second alternative explanation, the timing of the surges in public interest that we observed are consistent with the timing of StopChildMarriage's interventions - the first spike was in October 2013 when StopChildMarriage entered the public sphere and the second was in June 2015 shortly after the CC verdict (see Figure 2). Moreover, there was specific interest in the term pernikahan anak (the Bahasa term for "child marriage" that StopChildMarriage used in its campaign) rather than other, rival terms. In addition, our interview data show that many nascent grassroots groups refer specifically to StopChildMarriage in their activism. While we cannot rule out the possibility that the changes that we observed had other roots, our analysis of the available evidence suggests otherwise.

\section{DISCUSSION}

We set out to explore the puzzle of how organizations can successfully disrupt guarded institutions when they are unable or unwilling to dissent openly. This is a problem that many organizations encounter, but one which has rarely been a focus of the literature to date. It also represents a formidable task, particularly in light of the moral authority that typically characterizes such institutions and their guardians. Through an in-depth case study of an international children's rights organization's efforts to challenge the institution of child marriage in Indonesia, we developed a process model of institutional disruption in these circumstances. 
The model, illustrated in Figure 4, is a representation of our empirical observations. In this section, we abstract from these observations to articulate the new theory that we build from our case. We also consider the boundaries of our theory and the extent to which it is generalizable.

----------Insert Figure 4 about here----------

\section{Contribution 1: Organizational Strategies to Challenge Guarded Institutions}

Our first contribution is to conceptualize two strategies that organizations can deploy to disrupt guarded institutions when they are unwilling or unable to speak out publicly: the crafting of an alter ego - in our case, the alter ego took the form of a social movement that appeared to have emanated from the grassroots; and the use of this alter ego to incubate public dissent - in our case, by means of a high-stakes event. These strategies are novel: the existing literature has seldom systematically explored how organizations which are constrained in this way can challenge institutions that are guarded.

Thus, while institutional theorists have devoted considerable energy to the study of institutional disruption and change, they have mainly studied contexts where organizations have opportunities to engage in discursive work designed to undermine existing practices and legitimate new ones (e.g., Leblebici et al., 1991; Reay \& Hinings, 2005; Tracey, Phillips, \& Jarvis, 2011). These opportunities are unlikely to exist in institutional contexts coercively guarded by elites. At the same time, an important body of research has revealed how NGOs and other organizations advocate for change in repressive contexts (e.g., Ndegwa, 1996; Reinecke \& Donaghey, 2015; Scherer \& Palazzo, 2011). This work is significant because it is one of the few areas of management research where such contexts are explicitly examined. Crucially, however, it focuses on organizations that have a mandate, or at least a willingness, to speak out. Yet many organizations - such as $\mathrm{ICO}$ - are not in a position to contest prevailing institutions in this way. For these actors, the consequences of open dissent can be severe, especially if they are bound by 
agreements with local elites that limit their scope for action: the risk of arrest, censure or ejection may be deemed too great. In this subsection, we conceptualize two strategies that organizations may use in these circumstances.

Crafting an alter ego. This strategy involves the construction of an alternative public face, which allows challengers to guarded institutions to disguise their organizational affiliation, thereby shielding themselves from attack by local elites. Interestingly, an emerging body of research has sought to explore the dynamics of disguise and concealment within "non-secret organizations" (Costas \& Grey, 2014: 1424), some of which links to this finding. For example, Mair et al.'s (2016) study, discussed earlier, showed how an NGO working on water and sanitation projects in rural villages concealed its "principal interest", which was to address deeprooted patterns of inequality - a goal that some villagers "neither anticipated nor desired" (p. 2033). Moreover, Pache and Santos (2013) revealed how commercial actors who founded work integration social enterprises in France sought to make their ventures appear like social welfare organizations - a "Trojan horse" (p. 972) strategy designed to build legitimacy. More broadly, organizational identity scholars have considered a range of circumstances in which organizations might need to hide their 'true' selves or influence others' perceptions of them (Ginzel, Kramer, $\&$ Sutton, 2004). And the idea that organizations may need to shape how others view their actions, particularly in the context of stigmatizing or identity threatening events, underpins the literature on symbolic and impression management (Elsbach, 2014).

Crafting an alter ego resonates with these ideas but differs from them in the extent of the deception: it involves creating an alternative self rather than reshaping how an organization is perceived. The strategy comprises two tactics: secretive coalition building and feigning a social movement. The first of these - secretive coalition building - is well established in the literature: 
we know that organizations of different kinds build hidden relationships with others to promote their goals (Knoke \& Kostiuchenko, 2017). This can be difficult, because the motivations of the actors that are sympathetic to the cause being promoted may be unclear (see also, Rao \& Dutta, 2012). In our case, we saw that $I C O$ carefully surveyed the landscape of existing NGOs before reaching out to potential partners. This helped to create a quite intricate coalition structure that was organized across multiple layers and clearly defined each partner's capabilities and roles.

Crucially, secretive coalition building sets the stage for a second tactic to be enacted as part of this strategy: the feigning of a social movement. This involves constructing the appearance of a social movement that seems to have arisen from the grassroots but is actually deliberately fostered by the organization and its partners - a 'fake' social movement that is perceived as a 'real' social movement by the media and public. Even with a coherent coalition in place, the ability of challengers to effect change is severely hampered by the fact that members may be unwilling to operate openly in the face of traditional authority structures (Pye \& Pye, 2009). Our study suggests that challengers can overcome this limitation by masking their identities and mimicking the appearance and behavior of a social movement. In our case, the creation of StopChildMarriage - an online platform and group of frontline student activists that gave the impression of a social movement that arose organically - provided challengers with "the right to speak" (Phillips, Lawrence, \& Hardy, 2004: 643) and created a particular kind of "safe space" (Gamson, 1996: 27; see also, Mair, Marti, \& Ventresca, 2012; 2016; Rao \& Dutta, 2012; Vaccaro \& Palazzo, 2015) in which they could execute this right.

Incubation of public dissent. At first sight, the incubation of public dissent may not appear particularly surprising as a strategy for social change. Indeed, the creation, mobilization, and diffusion of activist groups has been a long-standing concern in social movement studies 
(Briscoe \& Gupta, 2016; Snow \& Soule, 2010; Snow, Soule, \& Kriesi, 2004; see also Lee et al., 2018). However, our case differs from existing research in a key respect. Specifically, the public dissent in our case was incubated by an organization with close ties to the political elite: ICO was not a grassroots NGO or social movement organization, and its ties to the establishment had consequences for how it could challenge the institution of child marriage in Indonesia.

Most notably, the incubation of dissent could not be done openly because the focal organization could not dissent openly. This had profound implications: it meant that ICO had to protest indirectly - to provoke public outrage via a high stakes event and the exploitation of its outcomes. As discussed below, the particular nature of the event may vary - in our case, it was the announcement of a legal decision - but it could equally take a different form. The key point is that the event is one of high stakes. Again, this is not a straightforward task because organizations that are unable to oppose authority cannot directly convene or stage such events which is why the crafting of an alter ego is so critical. We saw how ICO and its partners used its alter ego - StopChildMarriage - to force a judicial review, which then led to the announcement of the court's decision to the public, which only became a high-stakes event because of the preevent built up and its subsequent exploitation.

Indeed, the CC verdict would likely have passed with little fanfare if the challengers had not sought to first build expectations of a positive outcome for the judicial review, and then to undermine the arguments likely to be used in favor of child marriage before the judges had spoken: a 'routine' announcement thus became one that spawned widespread anger because StopChildMarriage had primed key audiences prior to the event and exploited the publicity generated by the event in its immediate aftermath. Crucially, then, a given event is not inherently "high stakes" and its impact on an institution is invariably uncertain (Grabher \& Thiel, 2015). 
Indeed, a key task facing challengers is to construct an event so that it comes to be seen as one of high stakes. This line of argument is consistent with Munir's (2005) observation that events are not necessarily disruptive in themselves; they have to be purposively constructed accordingly. The implication is that high-stakes events can often only be identified as such after they have been successfully exploited.

It is important to acknowledge that, combined, the two strategies we identify represent a way of making change that exists among a range of valid efforts: there may be many, equifinal paths to disrupt guarded institutions. We believe that the deception at the heart ICO's approach is most likely to be effective when organizations 1) have ties to local elites and rely on them in some way to fulfil their missions, and 2) lack the local legitimacy to engage grassroots actors directly. Adopting an alter ego allows organizations to protest without being identified, which means they can continue their other local projects and reduce the risk of retaliation by elites. And the advantage of crafting this alter ego by feigning a social movement is that it allows organizations to engage with grassroots actors, and thereby incubate public dissent, which is not typically possible for organizations with establishment ties and that may be viewed with suspicion by parts of the local population.

\section{Contribution 2: The Role of Organizations in Grassroots Mobilization}

Our second contribution is to build new insights about the role of organizations in grassroots mobilization. In developing this contribution, we move beyond the confines of our research question: we did not set out to build new theory about this issue, yet our findings call into question prevailing assumptions about the emergence of collective action.

Interestingly, the existing literature is largely predicated on the idea that there is a distinction between public mobilization that is fostered by 1) grassroots collective action, and 2) established organizations through astroturfed campaigns (Jordan \& van Tuijl, 2000; Ghai \& 
Vivian, 2014; Walker, 2014; 2016). Grassroots collective action is often considered as a pure form of mobilization (Castells, 1983). A core assumption is that such activism is organically emergent, with those participating in it politically excluded to varying degrees. Crucially, participation is presumed to be voluntary, with those involved neither incentivized materially nor coerced (Zellner, 2010). Social movement scholars have written extensively about the mobilization efforts of politically motivated grassroots groups (e.g., Polletta, 1998; Snow, Soule \& Kriesi, 2004; Soule 1997). However, organizations with connections to the establishment are largely excluded from this work: to the extent that they are considered, it is usually as the targets of protest. Several social movement scholars have begun to question this narrow focus. These authors point out that where movements seek to challenge deep-rooted structures of authority linked to institutions - such as "in the political, corporate, religious, or educational realms" (Snow et al., 2004: 9) - they tend to exhibit much greater diversity in their interests, and hence much greater heterogeneity and complexity in their organization (Briscoe \& Gupta, 2016). Nonetheless, research on the role of organizations such as ICO in grassroots mobilization remains markedly limited (Tarrow, 2013).

By contrast, astroturfing is often used as a pejorative term applied to organizations that adopt the strategies and tactics usually associated with actors who are politically excluded (Kraemer, Whiteman, \& Banerjee, 2013). It is a specific type of advocacy campaign designed to mobilize collective action that appears to emanate from the grassroots when it is actually strategically organized from the top down (Beder, 1998; Skoglund \& Böhm, 2016) ${ }^{10}$. While the term is usually associated with corporations, any type of organization can engage in astroturfing - including "labor unions, foundations, government agencies, and other advocacy groups"

\footnotetext{
${ }^{10}$ For example, Uber suffered severe reputational damage when it was revealed that the "grassroots" student campaigns advocating for "free markets" on several US university campuses were in fact organized by the company.
} 
(Walker, 2016: 272). An advocacy campaign is considered astroturfing if it is characterized by at least one of three characteristics: participants receive material incentives to take part in the campaign; participants make fraudulent claims or claims that they cannot verify; the sponsor is hidden allowing the campaign to masquerade as a genuine mass movement (Walker, 2014).

Our study questions the astroturfing-grassroots mobilization dichotomy: organizations can support the emergence of grassroots activism, strategically coordinating action without being motivated simply by self-interest as suggested by scholarship on astroturfing (e.g., Cho et al., 2011; Lee, 2010). In our case, ICO and partner NGOs worked hand in hand with local NGOs to form a cohesive activist coalition that combined diverse interests to campaign for a common goal. The institution at stake, child marriage, was problematized by the coalition acting under the guise of the 'movement' that it feigned. This institution was relatively uncontested in large parts of Indonesia prior to this point and became increasingly contested through the emergent activism that it subsequently engendered: $I C O$ 's actions ultimately inspired grassroots actors unconnected to the original coalition to begin their own efforts against child marriage, which allowed ICO and its partners to take a backseat role. Thus, the grassroots activism in our case was initially organized in a relatively top-down fashion, then transitioned to a blended structure that operated both from the top-down and the bottom-up, and ultimately became 'real' grassroots activism that was organized in a relatively bottom-up manner. In other words, the activism in our study was characterized by a mixture of strategic behavior by organizations and grassroots protest, i.e., a quasi-organic form of social movement whose activities could not be neatly categorized as astroturfed or grassroots. From this perspective, activism exists on a dynamic continuum from that which emanates organically from the grassroots, to that which are created through organizations acting strategically, and can move back and forth between them. 
This is an important insight, because it suggests that organizations which are not traditionally thought of as social movement organizations and which have connections to the establishment can play a key role in the creation of grassroots collective action. Intriguingly, the dynamics that we uncovered in our case - the shift from a (mostly) astroturfed campaign to (mostly) grassroots activism - runs counter to those revealed in existing studies of collective action in repressive contexts in which the reverse pattern is often evident. Indeed, existing work has shown convincingly how grassroots activity may develop into formalized social movement organizations (e.g., Vaccaro \& Palazzo, 2015).

Thus, ICO could be considered to have embarked on a social change initiative that in some respects resembled a traditional advocacy campaign, but which was fused with elements of astroturfing and grassroots organizing: the boundaries between these categories may be blurred, and it can be difficult to tell where astroturfing ends and grassroots activism begins. In presenting these arguments, we emphasize that while the campaign led by ICO helped spark grassroots activism that we would characterize as emancipatory, the same strategies could be used to foster the emergence of oppressive movements. In a contemporary world characterized by the rise of 'fake news' and extremism of different forms, the need to understand the role of organizations in mobilization takes on particular significance.

\section{Generalizability and Boundary Conditions}

It is important to consider the extent to which our theory is transferable to other organizations and contexts (Lincoln \& Guba, 1985). For example, with regard to our strategy of crafting an alter ego, in our case the masking and mimicking we observed were enacted through the feigning of a social movement. It is conceivable that challengers could take on other guises, such as the creation of a fake organization or hiding behind local NGOs without engaging activists directly. However, assuming the appearance of a social movement helps organizations to attract like- 
minded actors to support the change efforts. Moreover, because social movements come with the benefit of being perceived as speaking on behalf of a "critical community" of society (Rochon, 1998: 22ff.), adopting the guise of a social movement gives organizations the legitimacy to oppose authority. In other words, it allows organizations to claim to speak for 'the people'.

With regard to our second strategy of incubating public dissent, we have argued that the construction of a high stakes events represents a particularly effective way of provoking and fueling grassroots activism. But equally there may there be other tactics that serve as functional equivalents. For example, the distribution of a photograph (Chouliaraki \& Zaborowski, 2017), the publication of a book (Maguire \& Hardy, 2009), or the release of a documentary (Vasi, Walker, Johnson, \& Tan, 2015) might ultimately perform the same purpose. Or rather than specific events, perhaps ongoing discursive work disseminated through social media might also stoke outrage in a similar manner. Thus, while we think that high-stakes events are likely to be especially effective, we acknowledge the possibility that other tactics could be used in its place.

Also, both strategies rely heavily on digital technology. In Indonesia, the internet is regulated to a much greater extent than in the West, but it is subject to less censorship than elsewhere. This raises the question of whether $I C O$ could have enacted its strategies in countries such as Saudi Arabia where social media and internet usage is much more tightly surveilled. Certainly, it would have been more difficult to feign a social movement and to provoke public outrage if social media usage was curtailed. It is also less likely that grassroots activism would have spread to the same extent - much of this activity was out of ICO's control, which suggests that widespread access to digital technology may constitute an important boundary condition for our theory. That said, we note that online activism is often prevalent in countries such as China where authorities closely regulate and monitor the internet. Thus, while the strategies we identify may be more 
difficult to enact in these circumstances, we believe they would still be feasible.

In addition, there may be an important geographical boundary to our theory. We think that organizations such as ICO may play an especially important role in the generation of grassroots activism in the Global South because civil society in these contexts tends to be more fragile (Briscoe \& Gupta, 2016). By contrast, activists in the Global North tend to operate in contexts where the institutional landscape is more supportive of civil society. For example, Vaccaro and Palazzo's study of the movement against pizzo clearly unfolded in a repressive institutional setting, but it also occurred in a context where there is a long tradition of grassroots activism and a set of institutions that supports civil society (Cayli, 2013).

Finally, the guardians of the institution in our case were religious and political leaders who sought to protect what they saw as a cultural tradition. But other types of guardians - perhaps corporate or military leaders - may have different interests that they seek to protect in different ways. This, in turn, may require alternative strategies on the part of challengers. In this regard, there may be an opportunity to connect with recent work on institutional custodians (Dacin, Dacin, \& Kent, 2019; Montgomery \& Dacin, forthcoming), which considers how actors maintain institutionalized practices. While repressive contexts have not yet been a feature of this work, it may nonetheless offer insights for scholars interested in how organizations disrupt guarded institutions.

\section{CONCLUSION AND CRITICAL REFLECTION}

We have shown that challengers to a guarded institution may be able to catalyze change through the crafting of an alter ego and the incubation of public dissent - activities that allow for alternative perspectives on an issue to emerge, which create opportunities for grassroots activism to develop. While we believe these are important insights, we recognize that we cannot capture the full range and complexity of the dynamics at play through a single case study. Moreover, by 
structuring our analysis around the work of $I C O$, our findings arguably privilege its perspective on what happened, which makes the change effort appear somewhat strategically choreographed. It is important to acknowledge that, while $I C O$ had a clear ambition to disrupt the institution of child marriage, it could not predict with any precision the outcomes of the strategies that it deployed. We also realize that our findings raise important ethical questions about the extent to which it is appropriate for foreign organizations to impose their value systems on others: ICO took a stance against child marriage based on its own moral assumptions, which are firmly rooted in Western conceptions of family and community. We hope that other researchers will challenge and extend our findings, and in doing so explore more deeply the ethical implications of organizational campaigns such as the one led by ICO against child marriage in Indonesia. 


\section{REFERENCES}

Amis, J.M., Munir, K.A., \& Mair, J. 2017. Institutions and economic inequality. In: Greenwood, R., Oliver, C., Lawrence, T. and Meyer, R. (eds.) The SAGE Handbook of Organizational Institutionalism. Thousand Oaks, CA: Sage, 2nd edition.

Asia-Pacific News. 2018. Withheld to preserve anonymity, last accessed March 2018.

Assyaukanie, L. 2009. Islam and the Secular State in Indonesia. Singapore: Institute of Southeast Asian Studies.

Banks, N., Hulme, D., \& Edwards, M. 2015. NGOs, States, and Donors revisited: Still too close for comfort? World Development, 66: 707-718.

Baur, D. \& Schmitz, H.P. 2012. Corporations and NGOs: When accountability leads to cooptation. Journal of Business Ethics, 106: 9-21.

$B B C, 2017.28$ April. Available at: http://www.bbc.com/news/world-asia-39741891, last accessed January 2018.

Beder, S. 1998. Public relations' role in manufacturing artificial grassroots coalitions. Public Relations Quarterly, 43(2): 21-23.

Bowen, J.R. 2003. Islam, Law, and Equality in Indonesia: An Anthropology of Public Reasoning. Cambridge: Cambridge University Press.

Brechenmacher, Saskia. 2017. Civil Society Under Assault: Repression and Response in Russia, Egypt, and Ethiopia. Washington, D. C.: Carnegie Endowment for International Peace.

Briscoe, F. \& Gupta, A. 2016. Social Activism in and around organizations. The Academy of Management Annals, 10(1): 671-727.

Brummans, B.H.J.M., Putnam, L.L., Gray, B., Hanke, R., Lewicki, R.J., Wiethoff, C. 2008. Making sense of intractable multiparty conflict: A study of framing in four environmental disputes. Communication Monographs, 75(1): 25-51.

Bunting, A. 2005. Stages of Development: Marriage of Girls and Teens as an International Human Rights Issue. Social Legal Studies, 14(1): 17-38.

Butt, S. 2008. Polygamy and mixed marriage in Indonesia: Islam and the marriage law in the courts. In T. Lindsey (Ed.) Indonesia: Law and Society: 266-287. Annandale: Federation Press.

Butt, S. 2010. Islam, the State and the Constitutional Court in Indonesia. Pacific Rim Law \& Policy Journal, 19(2): 279-301.

Castells, M. 1983. The City and the Grassroots: A Cross-Cultural Theory of Urban Social Movements. University of California Press.

Cayli, B. 2013. Creating counterpublics against the Italian Mafia: Cultural conquerors of webbased media. Javnost-The Public, 20(3): 59-76.

Cho, C.H., Martens, M.L., Kim, H., \& Rodrigue, M. 2011. Astroturfing global warming: It isn't always greener on the other side of the fence. Journal of Business Ethics, 104: 571-587.

Chouliaraki, L. \& Zaborowski, R. 2017. Voice and community in the 2015 refugee crisis: A content analysis of news coverage in eight European countries. International Communication Gazette, 79(6-7): 613-635.

Collingwood, V. \& Logister, L. 2005. State of the art: Addressing the INGO 'legitimacy deficit'. Political Studies Review, 3(2): 175-192.

Cornelissen, J.P., Durand, R., Fiss, P.C., Lammers, J.C., \& Vaara, E. 2015. Putting communication front and center in institutional theory and analysis. Academy of Management Review, 40(1): 1-12. 
Costas, J. \& C. Grey. 2014. Bringing Secrecy into the Open: Towards a Theorization of the Social Processes of Organizational Secrecy. Organization Studies, 35(10): 1423-1447.

Dacin, M.T., Dacin, P.A., \& Kent, D. 2019. Tradition in organizations: A custodianship framework. Academy of Management Annals, 13(1): 342-373.

Davis, G.F., Morrill, C., Rao, H., \& Soule, S.A. 2008. Introduction: Social movements in organizations and markets. Administrative Science Quarterly, 53: 389-394.

Diani, M. 1992. The concept of social movement, The Sociological Review, 40(1), https://doi.org/10.1111/j.1467-954X.1992.tb02943.x

Doh, J.P. \& Guay, T.R. 2006. Corporate social responsibility, public policy, and NGO Activism in Europe and the United States: An institutional-stakeholder perspective. Journal of Management Studies, 43(1): 47-73.

Eisenhardt, K.M. 1989. Building theories from case study research. Academy of Management Review, 14: 532-550.

Eisenhardt, K.M. \& Graebner, M.E. 2007. Theory building from cases: Opportunities and challenges. Academy of Management Journal, 50(1): 25-32.

Elie, S. 2006. Anthropology, Post-colonial thought and positionality. Studies in Social and Political Thought, 12: 53-72.

Elsbach, K.D. 2014. Organizational perception management. Psychology Press.

England, K.V.L. 1994. Getting personal: Reflexivity, positionality, and feminist research. The Professional Geographer, 46(1): 80-89.

Fairclough, N. 1992. Discourse and Social Change. Cambridge: Cambridge University Press.

Fatwa N. 2010. 26 Maret 2010, NU Online. http://www.nu.or.id/post/read/30250/nu-fatwadeclares-underage-girls-can-marry-to-build-family-values, last accessed October 2016.

Flick, U. 2009. An Introduction to Qualitative Research ( ${ }^{\text {th }}$ edition). London: Sage.

Gamson, J. 1996. Safe spaces and social movements. Perspectives on Social Problems, 8: 27-38.

Garrison. J. 2000: From confrontation to collaboration: civil society-government-World Bank relations in Brazil. Washington DC: World Bank.

George, G., Howard-Grenville, J., Joshi, A., \& Tihanyi, L. 2016. Understanding and tackling societal grand challenges through management research. Academy of Management Journal, 59(6): 1880-1895.

Gershman, C. \& Allen, M. 2006. The assault on democracy assistance. Journal of Democracy, 17(2): 36-51.

Ghai, D. \& Vivian, J. 2014. Grassroots environmental action: People's participation in sustainable development. Routledge.

Ginzel, L.E., Kramer, R.M., \& Sutton, R.I. 2004. Organizational impression management as a reciprocal influence process: The neglected role of the organizational audience. Reprinted in (original 1993): Hatch, M.J. \& Schultz, M. (eds.), Organizational identity, pp. 223-274. Oxford: Oxford University Press.

Grabher, G. \& Thiel, J. 2015. Projects, people, professions: Trajectories of learning through a mega-event (the London 2012 case), Geoforum, 65: 328-337.

Gray, R., Bebbington, J., \& Collison, D. 2006. NGOs, civil society and accountability: Making the people accountable to capital. Accounting, Auditing, \& Accountability Journal, 19(3): 319-348.

Gray, B. \& Purdy, J. 2018. Collaborating for Our Future: Multistakeholder Partnerships for Solving Complex Problems. Oxford: Oxford Publishing.

GNB. 2014. Withheld to preserve anonymity, last accessed January 2018. 
Hall, S. 1997. Representation: Cultural Representations and Signifying Practices. London: Sage.

Hardy, C. \& Maguire, S. 2010. Discourse, field-configuring events, and change in organizations and institutional fields: Narratives of DDT and the Stockholm Convention. Academy of Management Journal, 53: 1365-1392.

Hosen, N. 2008. Online Fatwa in Indonesia: From Fatwa Shopping to Googling a Kiai. In G. Fealy \& S. White (Ed.), Expressing Islam: Religious Life and Politics in Indonesia: 159173. Singapore: Institute of Southeast Asian Studies.

IB Times. 2015. Withheld to preserve anonymity, last accessed October 2016.

Indonesia Demographic and Health Survey (DHS). 2012. Available at: http://dhsprogram.com/pubs/pdf/FR281/FR281.pdf, last accessed October 2016.

Indonesia Statistics Portal. 2015. Available via: http://www.statista.com/statistics/254456/ number-of-internet-users-in-indonesia, last accessed October 2016.

Indonesian Ulema Council (MUI). 2014. Withheld to preserve anonymity, last accessed October 2016.

Jakarta Post. 2014a. Withheld to preserve anonymity, last accessed October 2016.

Jakarta Post. 2014b. Withheld to preserve anonymity, last accessed January 2018.

Jakarta Post. 2016. Withheld to preserve anonymity, last accessed January 2018.

Jakarta Post. 2018. Withheld to preserve anonymity, last accessed March 2018.

Jones, G.W., T.H. Hull, T.H., \& Mohamad, M. 2011. Changing Marriage Patterns in Southeast Asia: Economic and socio-cultural dimensions. Abingdon: Routledge.

Jordan, L. \& van Tuijl, P. 2000. Political responsibility in transnational NGO advocacy. World Development, 28(12): 2051-2065.

Kamete, A.Y. 2009. Hanging out with "Trouble-Causers": Planning and Governance in Urban Zimbabwe, Planning Theory \& Practice, 10(1): 85-103.

Karim, L. 2016. Reversal of fortunes: Transformations in State-NGO relations in Bangladesh, Critical Sociology, 44(4-5): 579-594.

Katz, J.S. \& Katz, R.S. 1975. The new Indonesian marriage law: A mirror of Indonesia's political, cultural, and legal systems. American Journal of Comparative Law, 23(4): 653680.

Knoke, D. \& Kostiuchenko, T. 2017. Power Structures of Policy Networks. In J.N.Victor, A.H. Montgomery, \& M. Lubell (eds.), The Oxford Handbook of Political Networks. Oxford University Press. DOI: 10.1093/oxfordhb/9780190228217.013.3.

Kraemer, R., Whiteman, G.M. \& Banerjee, B. 2013. Conflict and astroturfing in Niyamgiri: The importance of national advocacy networks in anti-corporate social movements.

Organization Studies, 34(5): 823-852.

Lampel, J. \& Meyer, A.D. 2008. Guest editors' introduction: Field-configuring events as structuring mechanisms: How conferences, ceremonies, and trade shows constitute new technologies, industries, and markets. Journal of Management Studies, 45: 1025-1035.

Lang, S. 2013. NGOs, civil society and the public sphere. Cambridge: Cambridge University Press.

Langley, A. 1999. Strategies for theorizing from process data. Academy of Management Review, 24: 691-710.

Langley, A. 2007. Process thinking in strategic organization. Strategic Organization, 5: 271282. 
Langley, A. \& Tsoukas, H. 2010. Perspectives on Process Organization Studies. In T. Hernes, \& S. Maitlis (Eds.), Process, Sensemaking and Organizing: 1-27. Oxford: Oxford University Press.

Lawrence, T.B. \& Buchanan, S. 2017. Power, institutions and organizations. In R. Greenwood, C. Oliver \& T. B. Lawrence, The SAGE Handbook of organizational institutionalism (pp. 477-506). London: SAGE Publications Ltd.

Lee, M., Ramus, T., \& Vaccaro, A. 2018. From protest to product: Strategic frame brokerage in a commercial social movement organization. Academy of Management Journal, 61(6), published Online: 11 Dec 2018 https://doi.org/10.5465/amj.2016.0223.

Leblebici, H., Salancik, G.R., Copay, A., \& King, T. 1991. Institutional change and the transformation of interorganizational fields: An organizational history of the U.S. radio broadcasting industry. Administrative Science Quarterly, 36(3): 333-363.

Lee, C.W. 2010. The roots of astroturfing. Contexts, 9(1): 73-75.

Lev, D.S. 1996. On the Other Hand. In L.J. Sears (Ed.), Fantasizing the Feminine in Indonesia: 191-203. Durham: Duke University Press.

Levy, D. \& Scully, M. 2007. The institutional entrepreneur as modern prince: The strategic face of power in contested fields. Organization Studies, 28(7): 971-991.

Lincoln, Y.S. \& Guba, E.G. 1985. Naturalistic Inquiry. Newbury Park, CA: Sage.

Mair, J. \& Hehenberger, L. 2014. Front-stage and backstage convening: The transition from opposition to mutualistic coexistence in organizational philanthropy. Academy of Management Journal, 57(4): 1174-1200.

Mair, J., Martí, I., \& Ventresca, M.J. 2012. Building inclusive markets in rural Bangladesh: How intermediaries work institutional voids. Academy of Management Journal, 55(4): 819-850.

Mair, J., Wolf, M., \& Seelos, C. 2016. Scaffolding: A process of transforming patterns of inequality in small-scale societies. Academy of Management Journal, 59(6): 2021-2044.

Maguire, S. \& Hardy, C. 2009. Discourse and deinstitutionalization: the decline of DDT. Academy of Management Journal, 52(1): 148-178.

Mercer, C. 2002. NGOs, civil society and democratization: A critical review of the literature. Progress in Development Studies, 2(1): 5-22.

Merriam, S.B., Johnson-Bailey, J., Lee, M-Y., Kee, Y., Ntseane, G., \& Muhamad, M. 2001. Power and positionality: Negotiating insider/outsider status within and across cultures. International Journal of Lifelong Education, 20: 405-416.

Merton, R.K. 1972. Insiders and outsiders: A chapter in the sociology of knowledge. American Journal of Sociology, 78(1): 9-47.

Miles, M.B. \& Huberman, A.M. 1994. Qualitative Data Analysis: An Expanded Sourcebook ( $2^{\text {nd }}$ edition). London: Sage.

Montgomery, W. \& Dacin, M.T. forthcoming. Water wars in Detroit: Custodianship and the work of institutional renewal. Academy of Management Journal.

Munir, K. 2005. The social construction of events: A study of institutional change in the photographic field. Organization Studies, 26: 93-112.

Ndegwa, S. N. 1996. The Two Faces of Civil Society: NGOs and Politics in Africa. Hartford, CT: Kumarian Press.

Nghiem, L.T.P., Papworth, S.K., Lim, F.K.S., Carrasco, L.R. 2016. Analysis of the capacity of Google Trends to measure interest in conservation topics and the role of online news, PLOS ONE, 11(3): e0152802. https://doi.org/10.1371/journal.pone.0152802 
Pache, A.C. \& Santos, F. 2013. Inside the hybrid organization: Selective coupling as a response to competing institutional logics. Academy of Management Journal, 56(4): 972-1001.

Pettigrew, A.M. 1990. Longitudinal field research on change: Theory and practice. Organization Science, 1(3): 267-292.

Pettigrew, A.M. 1992. The character and significance of strategy process research. Strategic Management Journal, 13(1): 5-16.

Pettigrew, A.M. 1997. What is a processual analysis? Scandinavian Journal of Management, 14(4): 337-348.

Phillips, N., Lawrence, T.B. \& Hardy, C. 2004. Discourse and Institutions. Academy of Management Review, 29(4): 635-652.

Phillips, N., \& Lawrence, T.B. 2019. Constructing Organizational Life: How Social-Symbolic Work Shapes Selves, Organizations, and Institutions. Oxford: Oxford University Press.

Polletta, F. 1998. "It was like a fever..." Narrative identity and social protest. Social Problems, 45(2): 137-159.

Pye, L.W. \& Pye, M.W. 2009. Asian Power and Politics: The Cultural Dimensions of Authority. Cambridge, MA: Harvard University Press.

Rao, H. \& Dutta, S. 2012. Free Spaces as organizational weapons of the weak: Religious festivals and regimental mutinies in the 1857 Bengal Native Army. Administrative Science Quarterly, 57(4): 625-668.

Rao, H., Morrill, C., \& Zald, M.N. 2000. Power plays: How social movements and collective action create new organizational forms. Research in Organizational Behaviour, 22: 237281.

Reay, T. \& Hinings, C.R. 2005. The recomposition of an organizational field: Health care in Alberta. Organization Studies, 26(3): 351-384.

Reinecke, J. \& Donaghey, J. 2015. After Rana Plaza: Building coalitional power for labour rights between unions and (consumption-based) social movement organizations. Organization, 22(5): 720-740.

Reuters. 2018. Available at: https://www.reuters.com/article/us-pakistan-ngos/pakistan-tells-18international-ngos-to-leave-actionaid-idUSKCN1ME1N3, last accessed March 2019.

Robinson, O.C. 2011. Relational analysis: An add-on technique for aiding data integration in qualitative research. Qualitative Research in Psychology, 8(2): 197-209.

Rochon, T.R. 1998. Culture moves: Ideas, activism, and changing values. Princeton University Press.

Salim, A. 2007. Muslim Politics in Indonesia's Democratisation: The Religious Majority and the Rights of Minorities in Post-New Order Era. In R McLeod \& A Macintyre (Eds.) Indonesia: Democracy and the Promise of Good Governance. pp: 115-137. Singapore: Yusof Ishak Institute.

Scherer, A.G. \& Palazzo, G. 2011. The new political role of business in a globalized world: A review of a new perspective on CSR and its implications for the firm, governance, and democracy. Journal of Management Studies, 48(4): 899-931.

Schuessler, E., Rueling, C.C., \& Wittneben, B.B.F. 2014. On melting summits: The limitations of field-configuring events as catalysts of change in transnational climate policy. Academy of Management Journal, 57(1): 140-171.

Sewell, W.H. Jr. 1996. Historical events as transformations of structures: Inventing revolution at the Bastille. Theory \& Society, 25(6): 841-881. 
Siggelkow, N. 2007. Persuasion with case studies. Academy of Management Journal, 50: 2024.

Skoglund, A.J. \& Böhm, S. 2016. Wind power activism: Epistemic struggles in the formation of eco-ethical selves at Vattenfall. In H. Bulkeley, M. Paterson, \& J. Stripple (Eds.), Towards a Cultural Politics of Climate Change: Devices, Desires and Dissent (pp. 173-188).

Cambridge: Cambridge University Press. doi:10.1017/CBO9781316694473.012

Snow, D.A. \& Soule, S.A. 2010. A Primer on Social Movements (Contemporary Societies Series). New York: W.W. Norton \& Company.

Snow, D. A., Soule, S.A., \& Kriesi, H. 2004. Mapping the terrain. In D. A. Snow, S. A. Soule, \& H. Kriesi (Eds.), The Blackwell Companion to Social Movements: 3-16. Malden, MA: Blackwell.

Soule, S. 1997. The student divestment movement in the United States and tactical diffusion: The shantytown protest. Social Forces, 75(3): 855-882.

Spires, A.J. 2011. Contingent symbiosis and civil society in an authoritarian state: Understanding the survival of China's grassroots NGOs. American Journal of Sociology, 117(1): 1-45.

Staggenborg, S. 2010. Conclusion: Research on Social Movement Coalitions. In Van Dyke, N. \& H.J. McCammon (Eds.), Strategic Alliances: Coalition Building and Social Movements: 316-330. Minneapolis, MN: University of Minnesota Press.

Suddaby, R. \& Greenwood, R. 2005. Rhetorical strategies of legitimacy. Administrative Science Quarterly, 50(1): 35-67.

Tarrow, S. 2013. Contentious Politics. In: The Wiley-Blackwell Encyclopedia of Social and Political Movements. Wiley Online Library.

Tilly, C. 1978. From Mobilization to Revolution. New York: McGraw-Hill.

Tilly, C. 2004. Social Movements, 1768-2004, Paradigm Publishers, Boulder, CO, 262 pages.

Tempo. 2013. Withheld to preserve anonymity, last accessed October 2017.

The Economist. 2016. Title: Marrying minors in Indonesia: Islamic conservatism makes it harder to cut the number of child brides, available at: https://www.economist.com/news/asia/21703456- islamic-conservatism-makes-it-hardercut-number-child-brides-marrying-minors, last accessed January 2018.

The Interpreter. 2015. Comment to article. Withheld to preserve anonymity, last accessed October 2016.

Thomas, D.C. 2001. International NGOs, State Sovereignty, and Democratic Values, Chicago Journal of International Law, 2(2), Article 11.

Tracey, P., Phillips, N. \& Jarvis, O. 2011. Bridging institutional entrepreneurship and the creation of new organizational forms: A multilevel model. Organization Science, 22(1): 6080.

UNFPA. 2012. Marrying Too Young: End Child Marriage. New York: UNFPA Report. Available at: www.unfpa.org/end-child-marriage.

UNICEF Global Database. 2014. Available at: https://data.unicef.org/, last accessed October 2017.

Vaccaro, A. \& Palazzo, G. 2015. Values against Violence: Institutional change in societies dominated by organized crime. Academy of Management Journal, 58(4): 1075-1101.

Vasi, I.B., Walker, E.T., Johnson, J.S., \& Tan, H.F. 2015. “No fracking way!” Documentary film, discursive opportunity, and local opposition against hydraulic fracturing in the United States, 2010 to 2013. American Sociological Review, 80(5): 934-959.

Walker, E. T. 2014. Grassroots for Hire: Public Affairs Consultants in American Democracy. 
Cambridge: Cambridge University Press.

Walker, E.T. 2016. Between grassroots and 'astroturf': Understanding mobilization from the topdown. In: D. Courpasson \& S. Vallas, The SAGE Handbook of resistance (pp. 269-279). London: SAGE Publications Ltd doi: 10.4135/9781473957947.n14.

Wang, D.J. \& Soule, S.A. 2012. Social movement organizational collaboration: Networks of learning and the diffusion of protest tactics, 1960-1995. American Journal of Sociology, 117: 1674-1722.

Weber, K. \& King, B. 2013. Social movement theory and organization studies. In P. Adler, P. du Gay, G. Morgan, \& M. Reed (eds.), Oxford Handbook of Sociology, Social Theory and Organization Studies.

Whiteman, G. 2010. Management studies that break your heart. Journal of Management Inquiry, 19(4): 328-337.

Yaziji, M. \& Doh, J. 2009. NGOs and Corporations: Conflict and Collaboration. New York: Cambridge University Press.

Zald, M.N. \& McCarthy, J.D. (eds.) 1970. The Dynamics of Social Movements: Resource Mobilization, Social Control, and Tactics. Cambridge, MA: Winthrop.

Zeccola, P. 2011. Dividing disasters in Aceh, Indonesia: Separatist conflict and tsunami, human rights, and humanitarianism. Disasters, 35(2): 308-328.

Zellner, J.C. 2010. Artificial grassroots advocacy and the constitutionality of legislative identification and control measures. Connecticut Law Review, 43: 357.

Zietsma, C. \& Lawrence, T.B. 2010. Institutional work in the transformation of an organizational field: The interplay of boundary work and practice work. Administrative Science Quarterly, 55(2): 189-221. 
TABLE 1

Data Sources

\begin{tabular}{|c|c|c|c|c|c|}
\hline \multicolumn{2}{|l|}{ Interviews } & \multicolumn{2}{|l|}{ Observation } & \multicolumn{2}{|l|}{ Archival Data } \\
\hline Interviewee & Number & Site & Hours & Key Documents and Visuals & $\mathrm{pp} / \mathrm{min}$ \\
\hline$I C O^{*} \mathrm{HQ}$ & 27 & $I C O \mathrm{HQ}$ & 35 & ICO HQ Internal Documents & $1324 p p$ \\
\hline ICO Indonesia & 18 & $I C O$ Indonesia & 30 & ICO Indonesia Strategy Documents & 184 \\
\hline ICO Global Research & 1 & ACJL (lawyers) & 4 & ICO Indonesia Partner Mapping & 31 \\
\hline ICO Tech. Support & 1 & WR2 & 2 & ICO Indonesia Tech Team Documents & 53 \\
\hline ACJL (lawyers)* & 10 & WR3 & 3 & Constitutional Court Packets (Minutes) [translated] & 297 \\
\hline WR2* & 3 & WR4 & 5 & Judicial Review \& Amicus Curiae [translated] & 242 \\
\hline WR3* & 2 & GA2 Conference & 4 & Intergovernmental Agreements on Child Protection & 202 \\
\hline WR4* & 4 & DPR-RI (Parliament) & 2 & & \\
\hline WR5 ${ }^{*}$ & 1 & ICO Tech. Team & 2 & Newspaper Coverage & 519 \\
\hline WR6 ${ }^{*}$ & 1 & & & Blogs \& Social Media Coverage & 112 \\
\hline YA $^{*}$ & 1 & & & Google Trends Analysis of Public Interest & 12 \\
\hline $\mathrm{CSO}^{*}$ & 1 & ${ }^{*}$ Lombok NGO, their work & & & \\
\hline GA2* & 1 & in three villages, and (child & + & Books (2) on ICO’s History \& Governance & 290 \\
\hline Lombok NGO & 6 & bride) families for one week & & $\begin{array}{l}\text { Books (4), Academic Articles (24) on Politics, Legal } \\
\text { System \& Islam in Indonesia }\end{array}$ & 1649 \\
\hline Child Brides \& Husbands & 3 & & & Books (4), Academic Articles (15) on Marriage Law & 960 \\
\hline Indonesian Politicians & 9 & & & Reports and Articles (22) about Child Marriage & 1152 \\
\hline Islamic Scholars/Imams & 7 & & & & \\
\hline Individual Activists & 6 & & & Videos, Campaigns, Documentaries, TV Coverage & $420 \min$ \\
\hline ICO HQ [archival] & 3 & & & Live Debates \& Webinars about Child Marriage (10) & $950 \mathrm{~min}$ \\
\hline Interviews & 105 & Observation Hours & 90+ & $\begin{array}{l}\text { Archival Documents Pages } \\
\text { Archival Visuals Hours }\end{array}$ & $\begin{array}{c}7,027 \\
23\end{array}$ \\
\hline
\end{tabular}

* ICO pseudonym: large international children's rights and protection organization

*YA

${ }^{*} \mathrm{CSO}$

${ }^{*} \mathrm{GA} 2$ pseudonym: local Women's Health Foundation

pseudonym: local Women's Rights \& Anti-violence organization

*WR4 pseudonym: local Islamic Women's Rights Centre

* WR5 pseudonym: Indonesian Planned Parenthood Association

${ }^{*}$ WR6 pseudonym: local Children and Mother Health Movement organization pseudonym: local Independent Youth Alliance pseudonym: local Civil Society organization pseudonym: Indonesian Family Planning Board 
TABLE 2

Core Concepts, Empirical Themes, and Illustrative Data

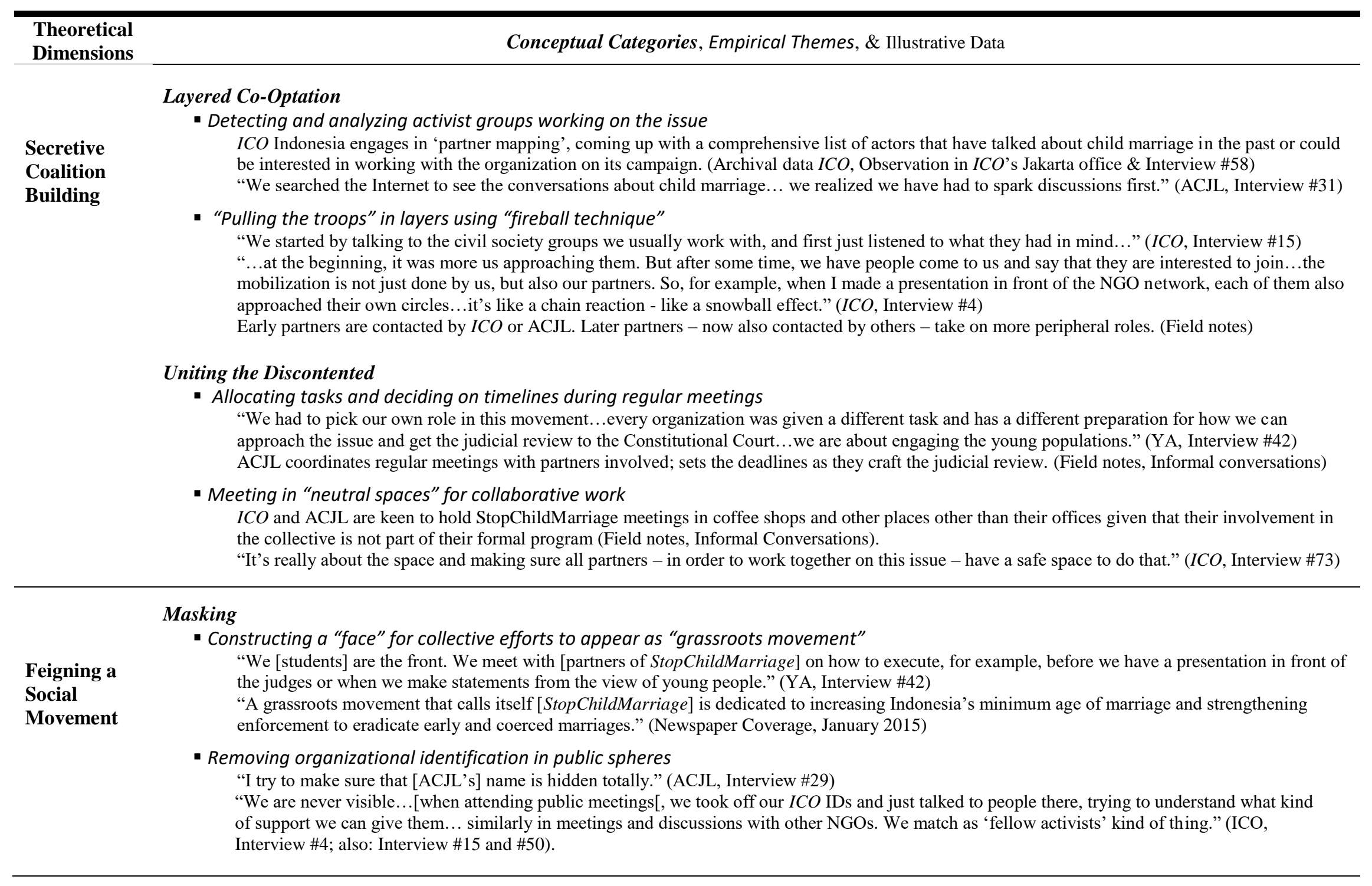




\section{Mimicking}

- Framing child marriage to be the roots of many related issues

"[StopChildMarrige $]$ argues that child marriage denies children their right to grow and develop, as well as their right to an education. They also say that teenage pregnancies often end in miscarriage, premature births and maternal deaths." (Newspaper Coverage, September 2014)

ICO mobilizes medical doctors and legal experts to write newspaper articles on the issue of child marriage (Field notes, Informal conversations)

- Imitating grassroots approach by initiating petitions, online campaigns, and hosting anti-child marriage events

$I C O$-affiliated youth groups initiate selfie-online-campaigns and other outreach-campaigns (e.g., posting group pictures of protests in Jakarta) where they post pictures of themselves demanding to end child marriage in Indonesia (Archival Data).

"[StopChildMarriage] has started an online petition on Change.org to increase the minimum age of marriage for girls [...] the petition has so far

gathered 13,000 signatures and counting." (Newspaper Coverage, January 2015)

- Reinforcing public association of StopChildMarriage with student groups

"Students challenge law" (Title of Newspaper, September 2014)

Many newspapers (national \& international) include pictures of protesting students and even children. (Archival data)

\section{Setting Expectations}

- Building positive momentum prior verdict via protest events

StopChildMarriage's youth group partner with other university groups to join in protests. (Archival data)

Provoking

Public

\section{Outrage}

how I can make them care about how we fight child marriage in Bandung." (Student Activist, Interview \#48)

ACJL reaches out to befriended activist groups to "grow the protests" (Field notes, Informal conversations)

- Mobilizing "allies" from higher profile community to join protests

Famous musicians, Islamic scholars, and known women's rights' activists show public solidarity with StopChildMarriage (Field notes [Observations \& Informal conversations])

"So I joined the group because I have a name, people know me, and I stand for women's rights" (Individual activist, Interview \#34)

- Generating positive expectations in the public

"A group of activists who are currently challenging the minimum age for marriage of 16 years old for females at the Constitutional Court are optimistic they will win their case." (Newspaper Coverage, September 2014)

Using the radio to "make ordinary people on the street talk about it" (Field notes, Informal conversations)

\section{Moral Confrontation}

- Filing judicial review to submit to the Constitutional Court

Judicial review detailing extensive arguments for marriage law revision filed by ACJL but officially by 'movement'. (Archival data)

"The group that filed the petition hopes the judicial review will eventually result in the current minimum age to be changed to 18." (Newspaper

Coverage, December 2014)

- Confront opposing groups prior and during CC hearings

"We made our statement on our view as young people [...] we showed the judges that the young people support us. Not only in Jakarta but also in many locales.” (YA, Interview \#42).

Detailed minutes on CC hearings reveal different positions on the issue; for example, "the group [StopChildMarriage] called [the religious group's] argument illogical”. (Archival data) 


\section{Proactive Aggravation}

- Fueling international and national outrage in media

"In its rage after the rejection by the Constitutional Court one of the plaintiffs, the head of the family planning association (Perkumpulan Keluarga Berencana Indonesia), stated that the government had openly legalized pedophilia." (Newspaper Coverage, August 2016)

ICO publishes emotional "human interest stories" on child brides. (Archival data)

Grassroots

Activism

- Increasing international pressures on Indonesia

ICO invites members of the ICO HQ to speak about how child marriage inhibits the achievement of the UN Sustainable Development Goals in Parliament. (Archival data)

Human Rights Watch publishes report titled "US Should Ramp Up Efforts to End Child Marriage Abroad.” (Archival data)

- Re-routing discussions from policy issue to plans for action

"We prepared the ground now and our new country program will be much bolder since the topic is not a taboo anymore, it's public discussion, our government partners recognize it as a problem. Now we can start talking publicly about what to do about it." (ICO, Interview \#4).

"We can use this situation and continue to make people talk about it, that's a success. And the success is also, for [YA], we can mobilize young people to act." (YA, Interview \#42)

\section{Reactive Amplification}

- Leveraging that regional governments amend local policies

Citing in reports that local governments change policies to prohibit pregnant girls' expulsion from high schools in their regions. (Archival data)

"Local government of Gunung Kidul, Yogyakarta, for example has issued "Perbup no.36/2015" to prevent child marriage after seeing that the numbers continued to increase. The same thing happened in Nusa Tenggara Barat province. The local governor issued "Surat Edaran Gubernur

No.150/1138/Kum" that recommends the best marriage age for women and men is 21." (Newspaper Coverage, August 2016)

- Encouraging student activists that want to spread the word across Indonesia

"During our assignments in the villages somewhere far from the city, we will tell them [villagers] to join us in our lectures about the dangers of child marriage" (Student activist, Interview \#48)

One of the local chapters of WR3 picked up the topic of child marriage in partnership with University students. (Field notes)

- Using the fact that CC Decision serves as platform for other organizations to mobilize

"People that stand against the court ruling now contact us from all over [...] they are from Medan, from Jakarta, Semarang - from all over Indonesia." (ACJL, Interview \#63)

Local partners connect to protest groups that emerge in several regions outside of Jakarta. (Archival data) 
FIGURE 1

A Timeline of the Empirical Context: Child Marriage in Indonesia, 1974-2019

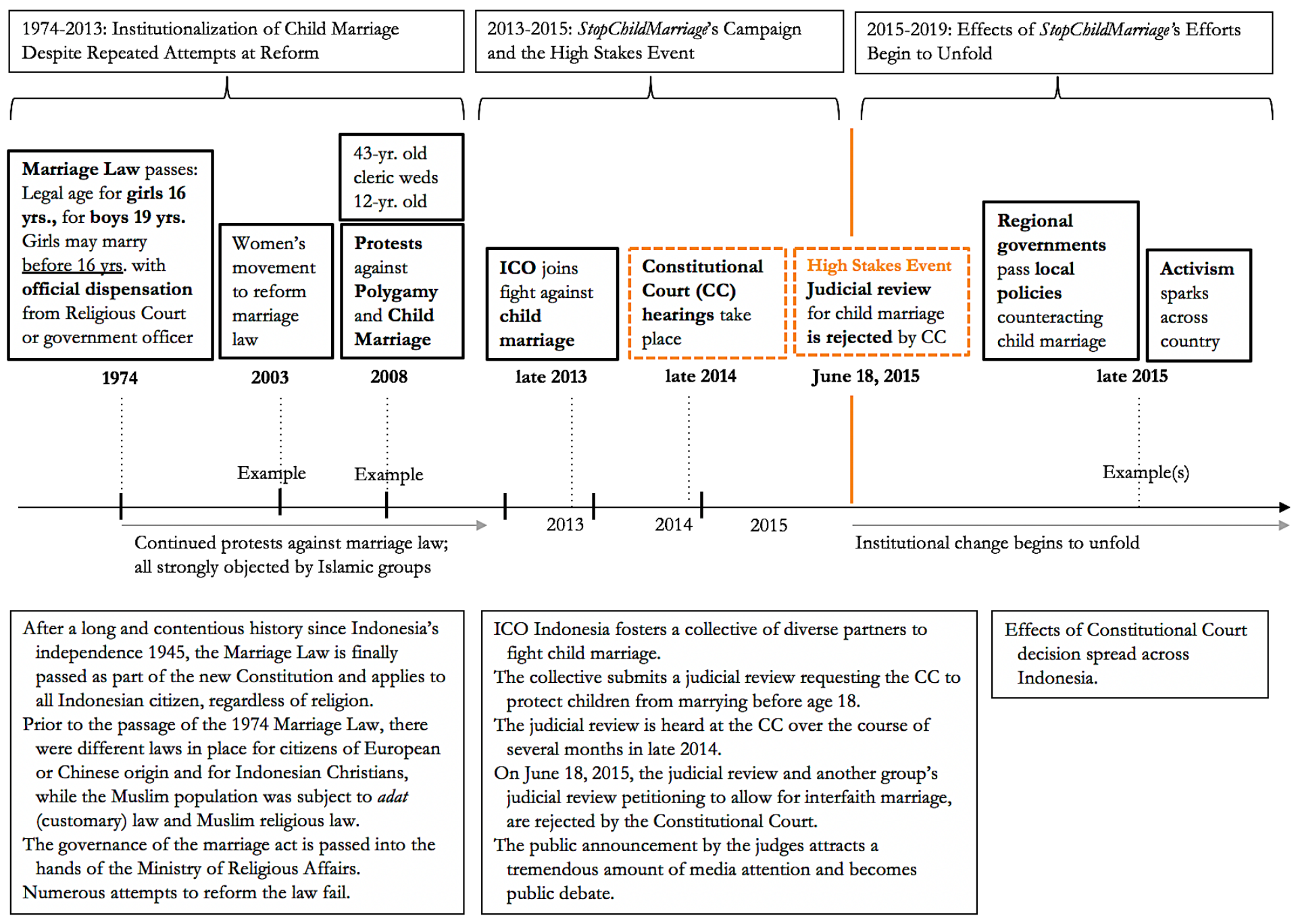


FIGURE 2

Relative Public Interest* in Child Marriage in Indonesia: Google Trends, 2009-2019

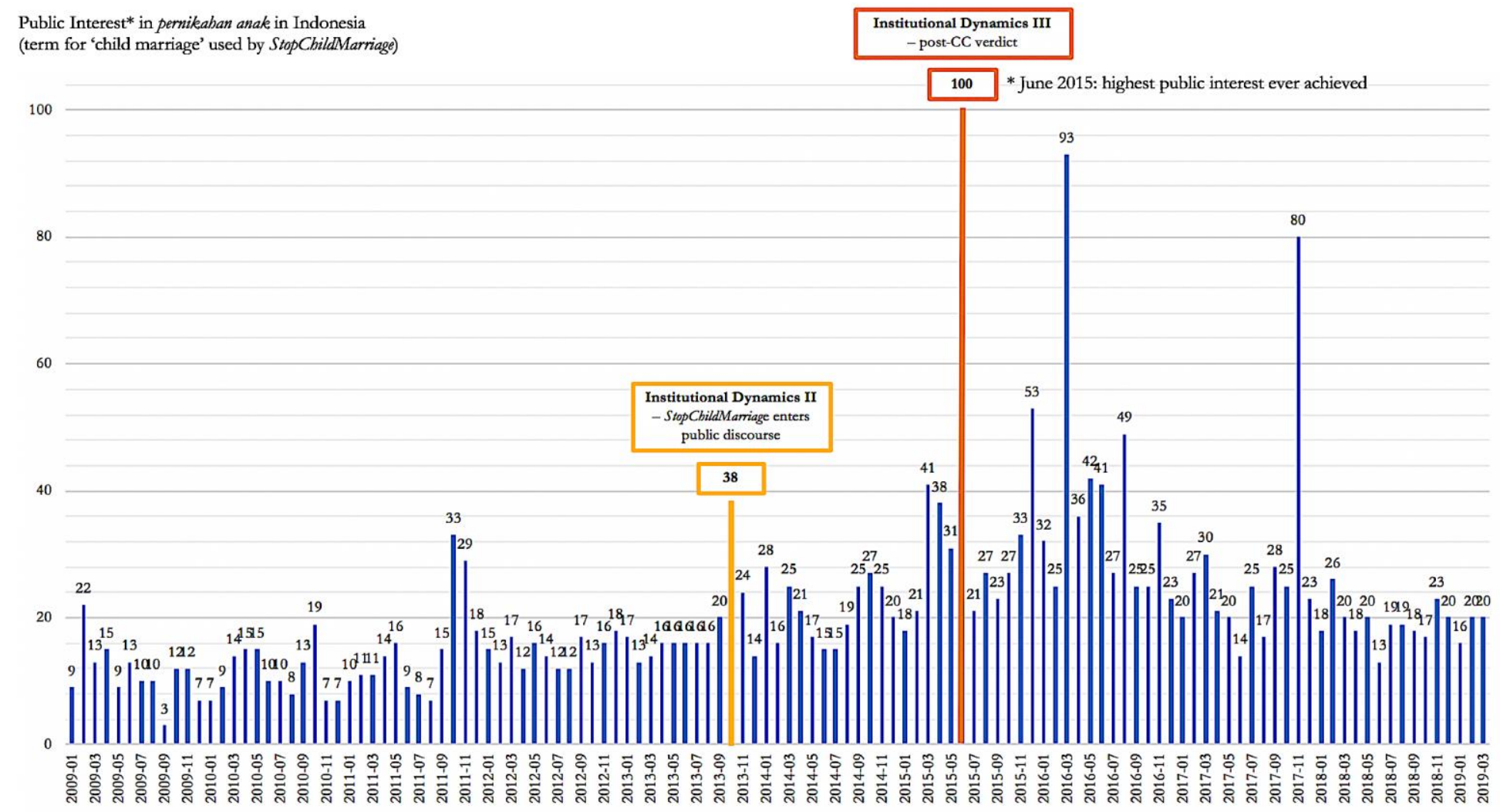

*Google Trends is an analysis tool that measures the relative public interest in a specific topic area or issue (Nghiem et al., 2016). "Public interest" is measured by taking the search volume of a key word (in a certain period) and dividing it by the highest search volume of a key word, then multiplying the outcome by 100 . Thus, a score of 100 on the $y$-axis = 'peak popularity'; 50 = half as popular; $0=$ the term was less than $1 \%$ as popular as the peak. We conducted the analysis in March 2019 .

Note: We also tested and controlled for other search terms used for 'child marriage' in Bahasa (e.g., perkawinan anak and kawin anak). They yield similar results to pernikahan anak prior to 2013; however, after mid-2013, pernikahan anak (the term StopChildMarriage used in its major campaigns) captured a significantly larger share in public interest while the interest in the other search terms remains flat (no increase, no decrease). To illustrate, in June 2015 (the month of the CC verdict), the term pernikahan anak yields a value of 100 (vs. value $=13$ for kawin anak and a value $=7$ for perkawinan anak). This corroborates our argument that StopChildMarriage (and the $\mathrm{CC}$ event it facilitated) was the main contributor to the surge in public interest (StopChildMarriage mainly used pernikahan anak in their campaigns). 
FIGURE 3

The Coalition's Internal Structure: A Representation of its Multiple Layers

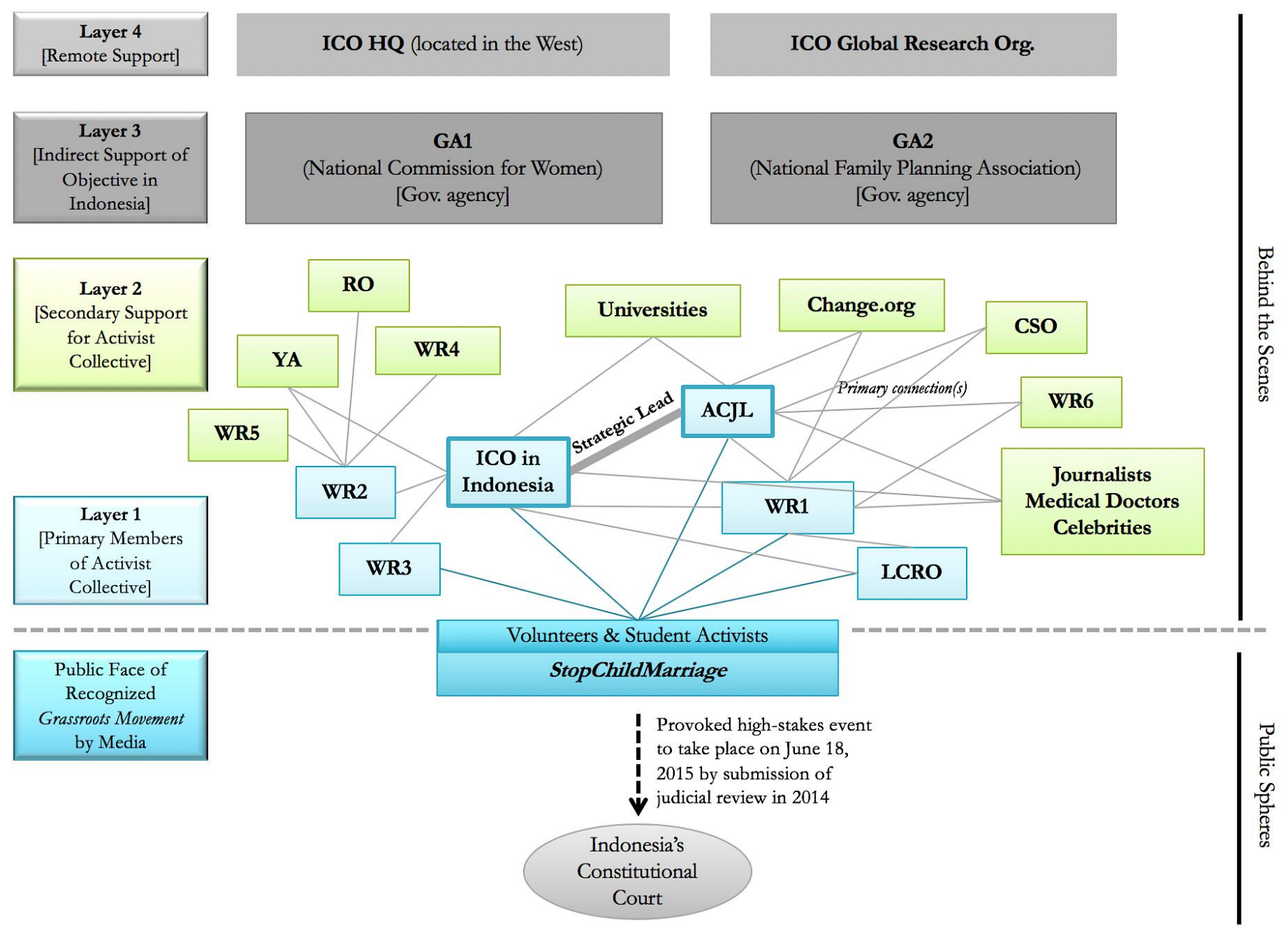


FIGURE 4

How Organizations Disrupt Guarded Institutions: A Process Model

Strategy 1: Crafting an Alter Ego

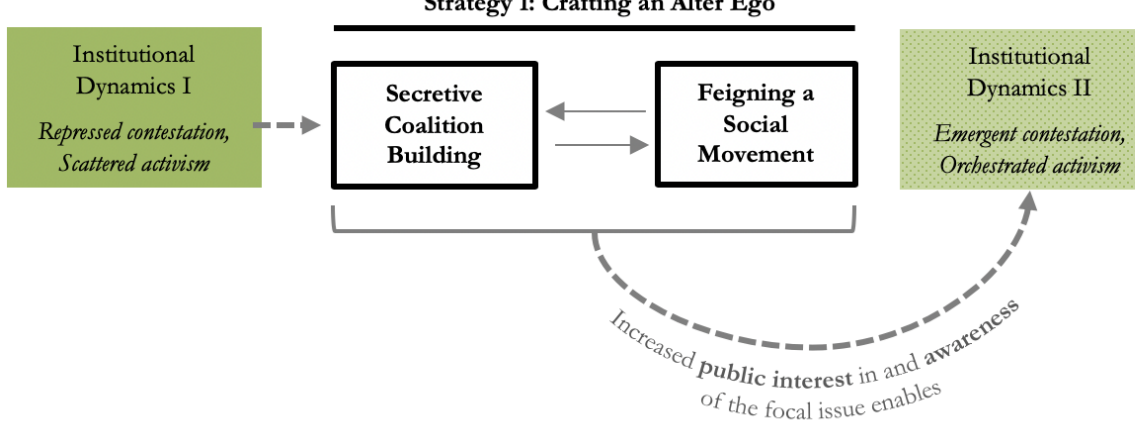

Strategy 2: Incubating Public Dissent

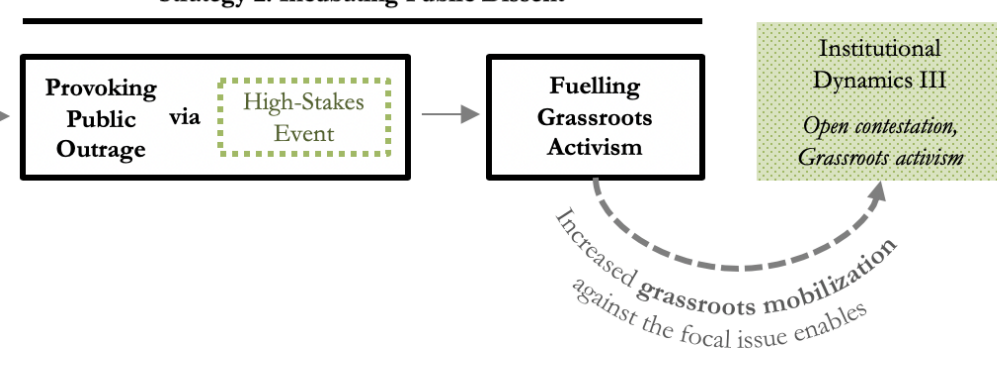




\section{AUTHOR BIOGRAPHIES}

Laura Claus (1.claus@ucl.ac.uk) is assistant professor of strategy and entrepreneurship at the UCL School of Management. She received her PhD from the University of Cambridge Judge Business School. Her research examines different organizational forms and strategies for social innovation and social change.

Paul Tracey (p.tracey@jbs.cam.ac.uk) is professor of innovation and organization and codirector of the Centre for Social Innovation at the University of Cambridge Judge Business School. He is also professor of entrepreneurship at the Department of Management and Marketing, University of Melbourne. He received his PhD from the University of Stirling. 